MPIKG Public Access

Author Manuscript

Published in final edited form as:

Antonietti, M., Lopez Salas, N., \& Primo, A. (2019). Adjusting the Structure and Electronic Properties of Carbons for Metal-Free Carbocatalysis of Organic Transformations. Advanced Materials, 31(13): 1805719. doi:10.1002/adma.201805719.

\title{
Adjusting the structure and electronic properties of Carbons for metalfree carbocatalysis of organic transformations
}

\author{
Markus Antonietti, Nieves Lopez-Salas, Ana Primo
}

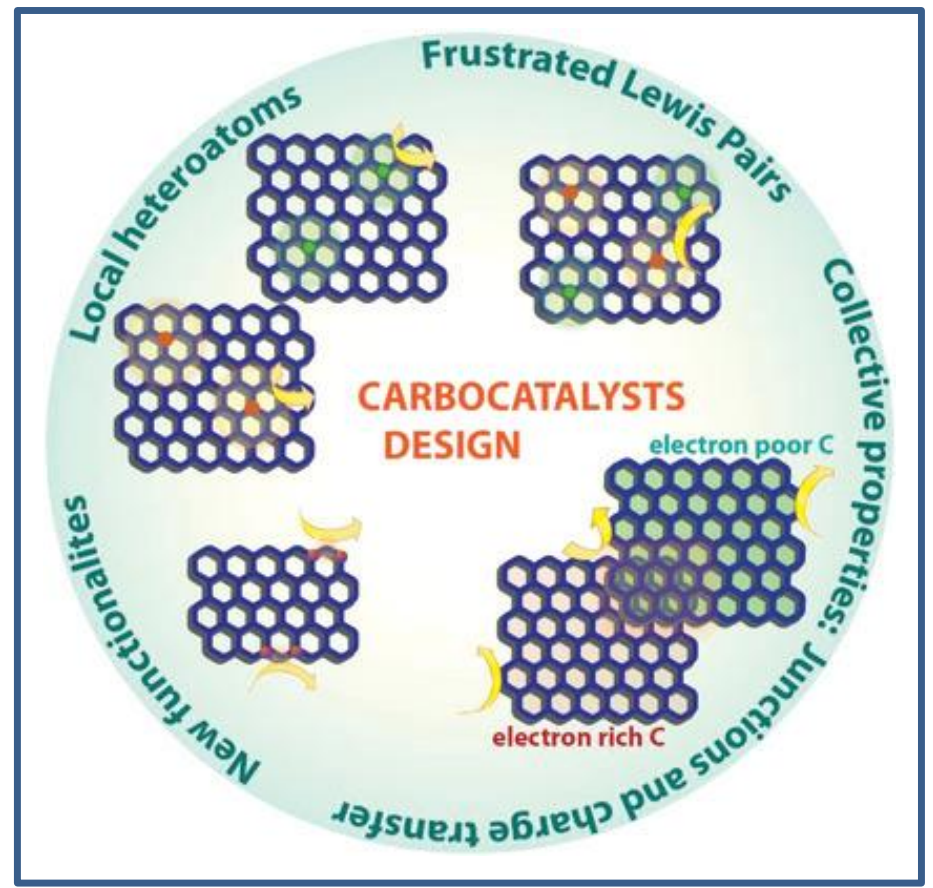

Carbon nanomaterials are not only excellent electrocatalysts but also powerful heterogeneous organocatalysts extending the spectrum of metal-based catalysis. The sometimes-forgotten history of these observations is first described, followed by highlights of the actual literature with respect to very diverse reaction classes. A personal outlook on potentialities and opportunities is given to close.

This article may be used for non-commercial purposes in accordance with Wiley Terms and Conditions for Self-Archiving. 


\title{
Adjusting the structure and electronic properties of Carbons for metal- free carbocatalysis of organic transformations
}

\author{
Markus Antonietti ${ }^{a *}$, Nieves Lopez-Salas ${ }^{a}$, Ana Primo ${ }^{b}$ \\ a Max Planck Institute of Colloids and Interfaces, Research Campus Golm, D-14424 \\ Potsdam, Germany; University of Potsdam, D-14424 Potsdam, Germany \\ ${ }^{\mathrm{b}}$ Instituto de Tecnología Química CSIC-UPV, Av. de los Naranjos s/n, 46022 Valencia \\ (Spain) \\ e-mail: antonietti@mpikg.mpg.de
}

\begin{abstract}
Carbon nanomaterials doped with some other lightweight elements were recently described as powerful, heterogeneous, metal-free organocatalysts, mostly in electrocatalysis. The present article restricts itself to review recent observations in traditional catalysis and tries to identify the underlying reaction mechanisms of the catalyzed organic transformations. Besides discrete active functional sites, the catalytic activity arises from the collective properties of conjugated nanocarbons and the electron transfer from and to catalytic centers and substrates. It will be shown that the learnings are tightly related to those of electrocatalysis i.e., the search for better electrocatalysts also improves chemocatalysis, and vice versa. Carbon-carbon heterojunction effects and some perspectives on future possibilities are discussed at the end.
\end{abstract}




\section{Introduction}

Catalysis is currently dominated by the use of transition metals, either as free ions, coordination complexes, clusters or as nanoparticles. Some of these transition metals are rare, and questions of sustainability make the search of alternatives a mandatory endeavour. In addition, many metals are not tolerant against functionality or are sensitive e.g. against water and sulfur compounds, and especially the growing fields of modern biorefinery and biomass processing are strictly limited by the use of catalysts that can satisfy these criteria. These are some of the reasons why there is a growing interest in exploring the potential of metal-free carbonaceous materials, or better solid organic materials with large specific surface area as heterogeneous organocatalysts.(1-5)

Carbon-based materials in catalysis as such is not a new topic, and there have been several reactions including removal of nitroxides, ozonizations and other oxidations that are known to be catalyzed by active carbons. Carbon, as an abundant element with diverse polymorphs, has always been extensively exploited for new structures that are not the common allotropes of graphite or diamond. However, with the recent significant improvements in synthetic tools to make more refined high surface area nanocarbons, the field has made a dramatic progress. $(4,6,7)$ For instance, carbon built up from $\mathrm{sp}^{2}$ bonds can be processed into highly porous solid or ideal two-dimensional (2D) sheets (graphene),(8) which gave carbon new applications ranging from electronics to energy storage.(9) On the other hand, $\mathrm{sp}^{2}$ carbons can also be modified electronically by bonding $\mathrm{p}$-block lightweight elements like $\mathrm{N}$, or $\mathrm{S}$, resulting in remarkable changes of physical and chemical properties.(10,11) The simultaneous generation of porosity and the integration of heteroatoms into the $\mathrm{sp}^{2}$ carbon network makes indeed most of the constituting atoms (i.e., including the active sites) of the material accessible for catalysis. Such "carbo catalysts" can 
meanwhile be easily and rationally prepared from polymerizable organics or even biomass derived molecules, then essentially implementing an elimination/cycloaddition scheme, in which the microstructure and composition can differ greatly depending on the specific synthesis.(12) Moreover, dopants like $\mathrm{N}$ or $\mathrm{S}$ can be not only incorporated by postfunctionalization, but also by copolymerization of functional entities which contain the targeted dopant atoms $(\mathrm{N}, \mathrm{S}$, or $\mathrm{P})$ all in their low oxidation state.(13) It is by no means a surprise then that such modified carbons have "revolutionized" the field of electrocatalysis, and other articles in this special issue describe the remarkable progress found, e.g., for the electrochemical oxygen reductions reaction (ORR), oxygen evolution reaction (OER), $\mathrm{CO}_{2}$ reduction reactions $(\mathrm{CRR})$ and nitrogen reduction (NRR). It is no exaggeration anymore that carbocatalysts have outpaced classical electrocatalysts a large extend, even driving alternative reactions which are otherwise practically impossible.

Catalysts based on transition metals promote many reactions in current-free "chemocatalysis". Such catalysts work either as a) acid/base catalysts; b) by using redox centers transferring electrons for oxidation and reduction, c) by transferring partial charges or polarization patterns, thus activating substrates by creating partial charges, and d) through the support of metastable intermediates transferring organic groups or fragments to a substrate. Indeed, nanocarbons can provide all those catalytic properties, even (when demanded) at the same time, by introducing acid/base, redox pairs, carbenoid structures, and by charge transfer interactions. This is also how the following paragraphs are organized.

\section{The early days: how carbocatalysis (potentially) started}

The catalytic activity of carbon as such is a very old chemical commonplace. Indeed, its origin can be traced out to as early as 1855 when J. Stenhouse observed that activated carbon was able to oxidize (in a large extent) a mixture of organic gases coming from putrefied 
biomass.(14) These results served as a motivation to F. Calvert who systematically studied the catalytic behaviour of charcoal for the oxidation of a variety of compounds in 1867. As a result, he found that charcoal was able to transform ethyl alcohol into acetic acid.(15) Afterwards a number of authors started studying the potential catalytic activity of active carbons (see for instance, reference 16; we thank D. S. Su for this reference). Even though results were very promising, carbocatalysis did not attract as much attention as it would attract nowadays.

Interestingly, with the arrival of high resolution electron microscopy, it was also found that many metal and metal oxide catalysts were in fact "activated" by a thin graphitic carbon shell which, to our opinion, opened the question on how these catalysts indeed worked i.e., their activity relied exclusively in the carbon shell, the metal underneath or was due to a synergetic effect of both. Based on these observations, Iwasawa et al. proposed nanostructured carbon materials as the catalytically active species for the oxidative dehydrogenation of ethylbenzene in 1973.(17) It was not until 2001 when it was probed that indeed pure carbons showed a much higher activity than the primary catalysts. $(18,19)$

In the meantime, in 1984, Boehm et al. reported the intrinsic catalytic activity of carbons for oxidation reactions as well as the strong dependence of this activity on the surface atomic composition of the carbon that included a special type of nitrogen-substitution.(20) From the contemporary point of view, the electron poor character of such carbons promoted the binding of electron rich substrates like dioxygen, and activated it by charge transfer. In 2007, Zhang et al. carefully studied with a combination of analytical techniques the geometrical parameters that affected the catalytic activity of different active carbons, nanodiamond, and carbon nanotubes. (21) This work culminated in a 2008 Science paper where carbon nanotubes modified with oxygen-containing groups on the surface were identified as more active for the oxidative 
dehydrogenation of alkanes to alkenes.(22) Interestingly, oxidation as well as phosphorylation of the carbon nanotubes turned out to activate these catalysts into the technically relevant levels.

In 2010 Bielawski et al. reported that graphene oxide was able to catalyse the oxidation of various alcohols and alkenes, and the hydration of various alkynes into their respective aldehydes and ketones. Besides proceeding under relatively mild conditions, samples also showed excellent yields and were easily recovered and reused by filtration. Interestingly, oxygen seemed to be the terminal oxidant agent.(23) Our own involvement in the field started at about the same time using imidazole modified carbons as Lewis base catalysts for Knoevenagel and Aldol condensation reactions.(24)

Evidences that tuning the morphology and surface chemistry of nanocarbons enhanced their catalytic performance and stability boosted carbon derived materials possibilities in catalysis and, as a result, an intensive effort on developing new carbocatalysts using carbon nanotube, fullerene, graphene and carbon nitride derived has been invested. (25-31)

\section{Acid Catalysis Using Carbocatalysts}

Acid sites in carbon nanomaterials are indeed mostly adventitious groups introduced in the material during its preparation procedure.(32) A typical case are sulfonic or sulfate groups introduced on graphene oxide (GO) due to a large excess of $\mathrm{H}_{2} \mathrm{SO}_{4}$ employed in graphite oxidation, as reported by Garcia and co-workers for the room-temperature ring opening of epoxides using methanol and other primary alcohols as nucleophile and solvent.(33) Interestingly, GO at $0.19 \mathrm{wt} \%$ exhibited $99 \%$ conversion with $97 \%$ selectivity towards the desired product in the ring opening of styrene oxide by methanol. It was confirmed that acidic impurities present in GO are responsible for the catalytic activity of GO. Indeed, the catalytic activity decreased when $\mathrm{S}$ was partially removed by thermal treatment at $200{ }^{\circ} \mathrm{C}$. 
Furthermore, the addition of pyridine in the reaction mixture stopped completely the reaction due to neutralization of acid sites. A comparable activity to that of GO was observed for the molecular strong acids $\mathrm{H}_{2} \mathrm{SO}_{4}$ and $p$-toluenesulfonic acid, while glacial acetic acid showed no conversion of styrene oxide, i.e. the acid sites at the carbon were rather strong

Room temperature acetalization of benzaldehyde by methanol could also be performed in quantitative yield and selectivity using GO as carbocatalyst.(34) In contrast, the use of other carbonaceous materials, such as graphite or AC (Norit A), highly porous metal-organic frameworks $\left[\mathrm{Fe}(\mathrm{BTC})\right.$ or $\mathrm{Cu}_{3}(\mathrm{BTC})_{2}(\mathrm{BTC}=1,3,5$-benzenetricarboxylate $\left.)\right]$, or acidic resins such as Amberlite XAD4 as catalyst resulted in low yields, again underlining the special role of the carbon as a support for the sulfonate group. It will be discussed below that an acid site along a joint electronic system is indeed to be seen different than the low molecular weight counterpart. Acidic GO was also reported to be an efficient carbocatalyst for the dehydration of fructose into $\mathrm{HMF}$, yielding $87 \%$ at $120{ }^{\circ} \mathrm{C}$ after 6 h.(35) The catalytic activity of GO declined rapidly after $\mathrm{GO}$ treatment above $200{ }^{\circ} \mathrm{C}$, while its activity is retained for GO treated below $150{ }^{\circ} \mathrm{C}$. In addition, the affinity of GO and Amberlyst-15 for fructose and HMF was evaluated by adsorption measurements, indicating that the amount of fructose adsorbed on GO is much higher than on Amberlyst-15. Acidic GO has also been reported as acid catalyst for the synthesis of polyoxymethylene dimethyl ethers (PODEn) from methanol and trioxymethylene.(36) It was proposed that the active sites are the combination of the sulfonic groups and the hydroxyl and carboxyl groups present on the surface of GO. Acidic GO was also efficient to promote in high yields ring opening reactions of chiral aromatic epoxides by indoles in regio/enantioselective manner in solvent- and metal-free conditions.(37) The Friedel-Crafts products were obtained with yields of the range of $25-80 \%$ and enantioselectivity up to $99 \%$. It was believed that the presence of different acid functionalities on the carbocatalyst surface activates the epoxide ring-opening and forms an 
incipient carbocation that reacts with the nucleophilic carbon of the indole. Furthermore, the high stereoselectivity achieved in all cases with complete inversion of stereochemistry strongly suggests that no free-carbocation is formed, but a surface-bound charged state.

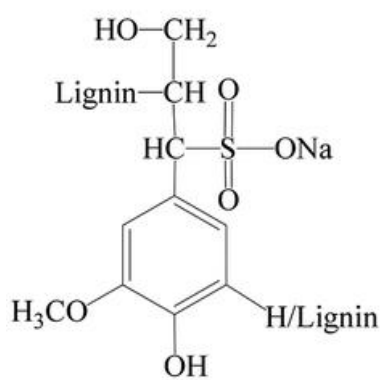

Na-Lignosulfonate (LS)
1) freeze drying

2) mild pyrolysis

3) $\mathrm{H}^{+}$exchanging (dil. acid)

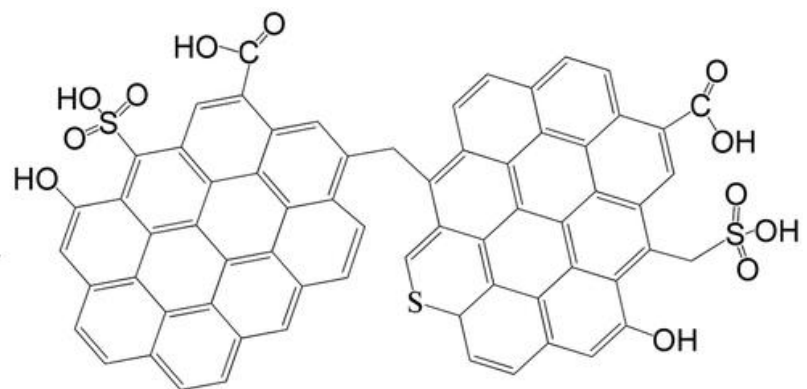

Sulfonic carbocatalyst $\left(\mathrm{C}-\mathrm{SO}_{3} \mathrm{H}\right)$
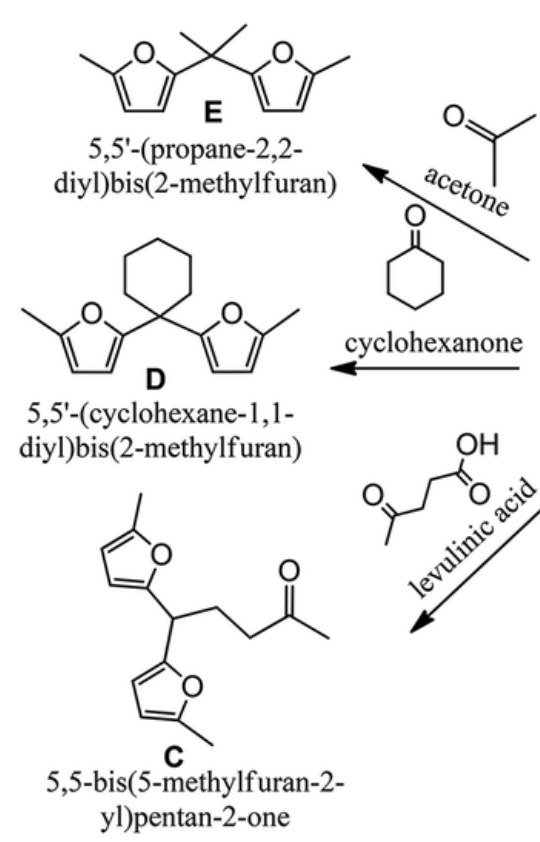

cyclohexanone

$5,5^{\prime}$-(cyclohexane-1,1diyl)bis(2-methylfuran)
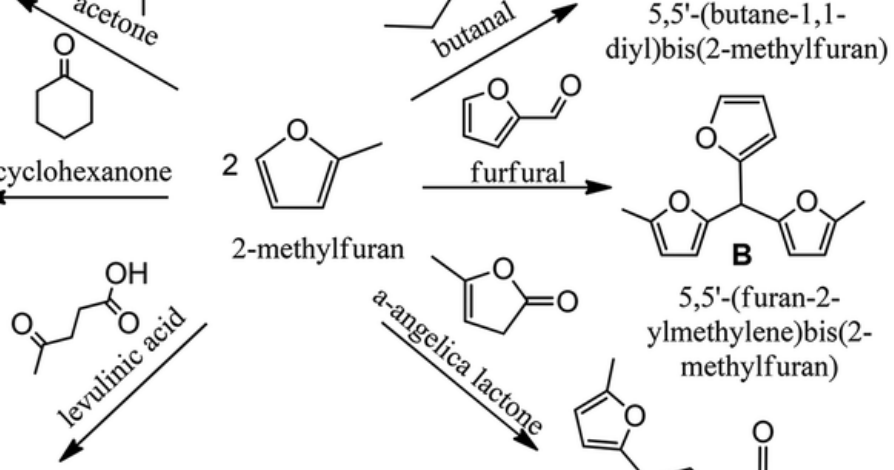

2-methylfuran

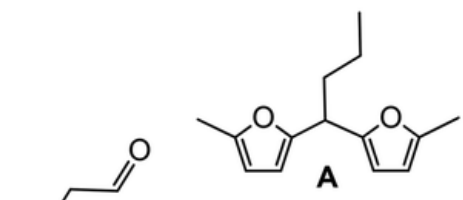

$5,5^{\prime}-$-(butane-1,1diyl)bis(2-methylfuran)

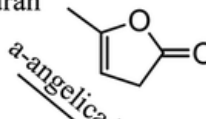

5,5'-(furan-2ylmethylene)bis(2-

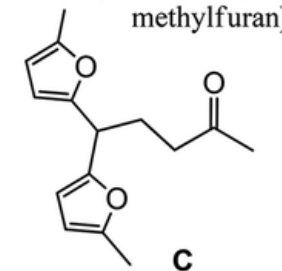

5,5-bis(5-methylfuran-2yl)pentan-2-one

Side reaction (slow)

3

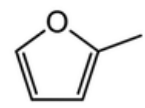

2-methylfuran trimerization

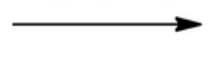

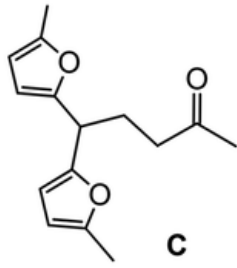

C

tris(5-methylfuran-2- 5,5-bis(5-methylfuran-2yl)methane yl)pentan-2-one

Figure 1. a) Synthesis of an acidic catalyst made by gentle carbonization from sulfonated lignin; b) some acid catalysed aldol reactions based on the biorefineryplatform molecule methylfuran (taken with permission from ref. 40). 
A remarkably interesting case is given by the work of Konvar and Mikkola where sulfonated Kraft lignin, a side product of paper manufacturing, was carbonized at high temperature to end up with highly porous, sulfonated, carbonaceous resins (see for instance Figure 1).(38) Such acid resins turned out to be unusually stable allowing usage temperatures of up to $200{ }^{\circ} \mathrm{C}$ under chemical load. Resins were later also used for the heterogeneous catalysis of transesterification reactions towards high value monoglycerides (39) and the carbon-carbon coupling of biobased furanes to branched $\mathrm{C}_{16}-\mathrm{C}_{18}$ petrochemicals.(40) The described performances are along with the very best acid catalysts as such currently found in the literature.

\section{Base Catalysis Using Carbocatalysts}

Base catalysts promoting the formation of carbon-carbon coupling are also of great importance in chemical synthesis (e.g., Knoevenagel condensations, transesterifications or Aldol condensations). Active base sites are also generally induced by functionalizing the carbonaceous network with foreign heteroatoms such as nitrogen and oxygen. When seeking solid base catalysts, a straight forward choice is trying to mimic homogeneous superbase catalysts chemical motifs. Indeed, well known proton sponges 8-diazabicyclo[5.4.0]undec-7ene (DBU) or 1,5,7-triazabicyclo[4.4.0]dec-5-ene (TBD) share a $\mathrm{N}-\mathrm{C}=\mathrm{N}$ bond. Different nitrogen rich carbonaceous materials with similar structures have been used as base heterogeneous catalysts. For instance, in 2008 Makowski et al., reported that cross-linked mesoporous poly(benzimidazole) was able to catalyse a variety of Knoevenagel condensation reactions providing that the catalyst was porous and deprotonated after synthesis.(41) Later, in 2011, we also reported the catalytic activity of deprotonated mesoporous graphitic carbon nitride for different Knoevenagel condensation and transesterification reactions.(42) Despite being catalytic active, as prepared mpg- $\mathrm{C}_{3} \mathrm{~N}_{4}$ exhibited unsatisfactory results most likely due 
to protonation of nitrogen functionalities. Since the deprotonation by simple thermal treatment lead to the collapse of the porous structure, chemical treatment with $\mathrm{tButOK}, \mathrm{KOH}$ and $\mathrm{K}_{2} \mathrm{CO}_{3}$ was performed. The result was a large increase in the catalytic activity of the samples as compared by running a model Knoevenagel reaction of benzaldehyde with malonitrile reaching conversions of $89 \%$ after $2 \mathrm{~h}$ at $70^{\circ} \mathrm{C}$ and a selectivity of $98 \%$. However, when aromatic aldehydes where substituted by less reactive ketones the conversion was poorer $(30 \%$ conversion after $19 \mathrm{~h})$ highlighting the relatively low basicity of the materials.

Other based catalysed reactions lacking more efficient, stable and selective catalysts which however have not been too extensively explored using carbocatalysts are basemediated ring opening polymerization, transesterfication reactions (such as the synthesis of biodiesel, see for instance ref. 43,44$)$ or the cycloaddition of $\mathrm{CO}_{2}$ to an epoxy-compound to form cyclic polycarbonates.(45) The last two reactions are a key stone on biodiesel production and $\mathrm{CO}_{2}$ fixation respectively and, in both cases, the presence of a heterogeneous base catalyst is a massive processing advantage. Indeed, some $\mathrm{N}$-doped or base modified carbons have already been described for this purpose. For instance, in 2010 Titirici et al. reported the preparation of mesoporous and highly functionalized carbons via hydrothermal carbonization of glucose and vinyl imidazole. Such carbons were not only active for Knoevenagel condensation of benzaldehyde with malonitrile (yielding over $98 \%$ at $80^{\circ} \mathrm{C}$ after $12 \mathrm{~h}$ ) but also for transesterification reactions (yielding over $50 \%$ at $150^{\circ} \mathrm{C}$ after $72 \mathrm{~h}$ ) without being neither structurally nor chemically affected.(46) In 2012, Thomas et al. used covalent triazine frameworks as catalysts in the cycloaddition of $\mathrm{CO}_{2}$ to epichlorohydrin obtaining full conversion of the initial epoxide and up to $95.8 \%$ selectivity at $130^{\circ} \mathrm{C}$ when the sample exhibiting the larger surface area and more basic framework (i.e., pyridine-based) was used as catalyst.(47) 
It is to be mentioned that the so called "basic carbons" are well known and developed in sorption science (48), as they are needed for the sorption of acidic impurities in air and water cleaning. Interestingly, some authors give evidence for a purely aromatic carbon-based base site on the basal planes (48), i.e. the interaction takes place between an electron rich carbon pool and the hydronium ion via some type of charge-transfer interaction. This binding is indeed very strong and active at already low acid concentrations, i.e. equipped with a high base strength. This discourse about the nature of basic sited in carbons was then later reviewed in (49). In the course of the overall discussion, it became clear that C-basic carbons are usually generated by reduction, i.e. they are electron rich (see Scheme 2).(50) This will be comparatively discussed below.

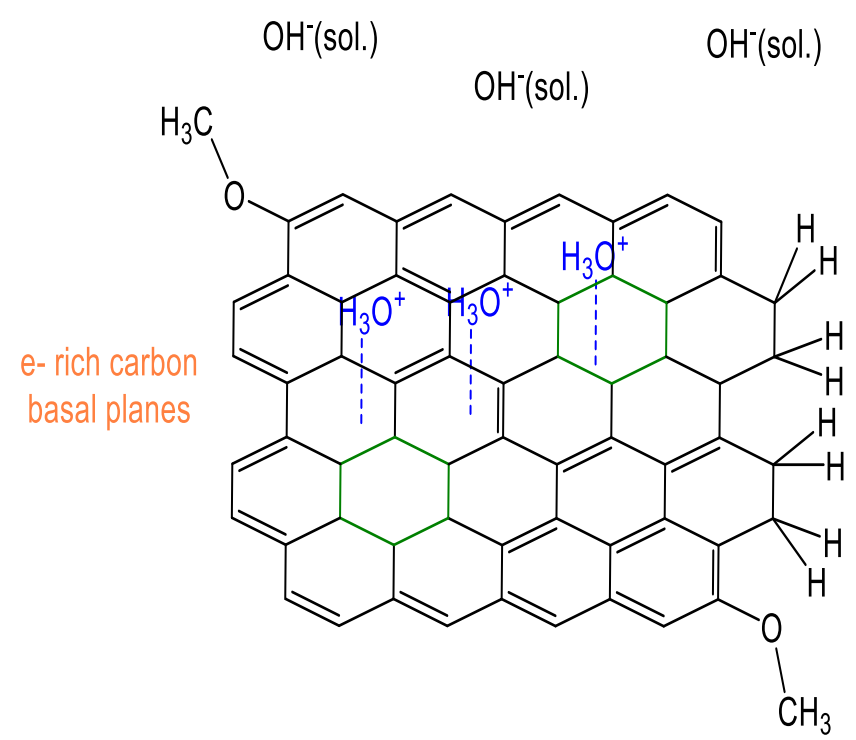

Scheme 2. scheme representing interaction between protons and electron rich carbon basal planes, this creating and effective basicity.

For catalysis, Perozo-Rondon et al described the use of highly basic carbons with a $\mathrm{P}_{\mathrm{K}} \mathrm{B}$ $=11.2$ for dihydropyrinidine synthesis.(51) Remarkably the heterogeneous materials were at least comparable with the best low molecular weight systems, if not clearly superior. Rubio- 
Gomez et al. used basic activated carbons for the synthesis of alpha-beta- unsaturated nitriles.

It is worth to mention that yield and selectivity of base carbocatalysts in all reactions are very high, making the materials already today a feasible choice.

\section{Carbene-Catalysis in appropriately substituted carbon materials}

Carbenes are among the most strongly basic/nucleophilic sites in organic chemistry and are for instance also known to ligate very strongly metal centres, as in the well-known Aucarbenes (53). We usually take it as given that carbon materials are composed of carbon with four valences, but the special electronic properties of modified carbons indeed can make of hetero-element stabilized carbenes regularly occurring structures in a carbon network. Though hardly known, naturally occurring biomolecules such as xanthine bases, adenine and other related compounds as caffeine form stable carbenes upon alkylation under basic conditions even in water (54) and, of course, a caffeine-like subunit in a carbon would do exactly the same. Heterocyclic carbenes (e.g., nitrogen-heterocyclic carbenes - NHC), are known since long time as catalyst of enzymatic processes (55). In particular, those heterocyclic carbenes derived from thiazolium are maybe the most prominent ones (see Scheme ), as they catalyse the conversion of pyruvate into acetyl coenzyme A which is one of the most important biological processes (56). 
A)<smiles>[R7]N1C=CN([R1])C1</smiles>

$\mathrm{NHC}$

C)

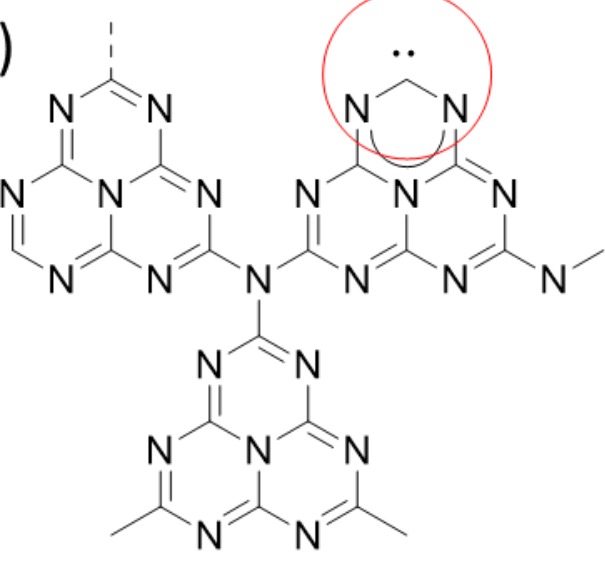

B)<smiles></smiles>

D)

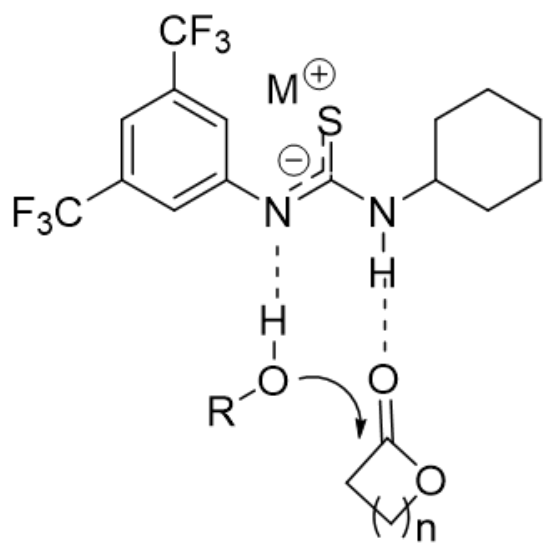

Scheme 3 - a) Representation of nitrogen-heterocyclic carbenes; b) formation of carbenes from caffeine upon alkylation under basic conditions; c) carbene-like site in etched g- $\mathrm{C}_{3} \mathrm{~N}_{4}$; d) heterocyclic carbenes derived from thiazolium promoting lactone ring opening.

The use of N-carbenes as organocatalysts in sustainable, metal-free polymer synthesis was reviewed by Taton et al. (57) and Waymouth et al. (58) Later, Taton extended this work later to polymer-based and framework-based N-carbenes, which indeed showed some enzyme-like chemical reactivities (59). Waymouth on the other hand introduced the concept of modified urea and thiourea moieties for an $\mathrm{N}$-carbene like reactivity and showed the superiority of those framed structures in base catalysis (60). All these cases are admittedly still in low molecular weight compound and polymer space, but based on this information it is expected to find carbene-like and (thio)imidate chemistry and reactivity in co-doped carbon materials, especially in those containing high nitrogen, sulfur and oxygen contents. 
In the context of carbene formation, also the periphery of $\mathrm{g}-\mathrm{C}_{3} \mathrm{~N}_{4}$ can become alike to NHCs if the corresponding carbon atoms are activated with appropriate functionalities and etching schemes (Scheme b) illustrates this type of N-heterocyclic carbenic center. Indeed, first experiments indicate that amine-poor carbon nitride can bind and photochemically reduce $\mathrm{CO}_{2}$ from the gas phase (61), while the same non-etched material cannot.

Inspired by this role in biochemical processes, also organocatalysis has exploited NHC as metal-free catalysts for various organic reactions (62). NHCs can be easily generated from the corresponding azolium heterocycles (either as low molecular weight compounds or as subunits in polymer frameworks and carbons) by deprotonation with bases. Although the most general use of NHC is as electron-rich ligands of metals ions to develop highly catalytically active metal complexes, NHCs can also exhibit catalytic activity by themselves in the absence of transition metals. Among the most general reactions of carbenes, oxidative activation of aldehydes to carboxylic acids and esters is considered to be an important one.

This complements the catalytic importance of carbenes and the related alkyl-urea based superbases in transesterification and lactone ring opening discussed above. It is very likely that the presence of these carbene-like defects in highly doped carbon materials as well as in both in modified $\mathrm{g}_{-} \mathrm{C}_{3} \mathrm{~N}_{4}$ can exhibit catalytic activity that parallels the behaviour of molecular NHCs. However, the development of all those possibilities is still in its infancy, and we predict potential breakthroughs in such materials.

\section{Oxidation, Reduction and Redox-Catalysis}

\section{Metal free carbonaceous materials in oxidations}

Catalytic oxidation of organic compounds using green oxidizing reagents is usually promoted by transition metals that either act as Lewis acid, enhancing the electrophilicity of 
the oxidant or promote the oxidation by swinging between two oxidation states (63). To show the general usefulness of metal-free catalysis, promotion of oxidation is one of the most requested target reactions.

In this context, aerobic oxidations of organic compounds can occur through at least two general mechanisms, Type I and Type II. (64) In the Type I pathway, also known as "autooxidation", the key reaction intermediate is a carbon-centered radical that reacts with ground-state triplet molecular oxygen giving a peroxyl radical. Subsequently the peroxyl radical can abstract one hydrogen atom from the substrate, forming an organic hydroperoxide and new carbon center radical. Therefore, this Type I autooxidation is a chain reaction, in which the important mechanistic events is the first generation of the carbon radical. Many carbon materials can indeed act as solid radical initiators due to electronic structure at edges and defects within the structure. The radicals not only are stabilized by the highly conjugated $\mathrm{sp}^{2}$ carbon structure but also they are further stabilized when allocated at appropriate edge positions (65) which allow them to easily react with oxygen without any relevant material decomposition.

A model oxidation reaction is the promotion of benzylic hydrocarbon autoxidation. Graphene oxide (GO) is a typical choice for this reaction (66), however it requires to be in a large excess (in weight) with respect to the substrate, i.e. it cannot really be considered to be catalytic. In this context, it was found that defective and doped graphenes can also promote the autooxidation of benzylic hydrocarbons, however with only a few percent in weight with respect to the substrate (67). Similarly to graphene, boron doped $\mathrm{g}-\mathrm{C}_{3} \mathrm{~N}_{4}$ has also been reported as an efficient promotor for the oxygenation of benzylic hydrocarbons (68). It was proposed that the effect of $\mathrm{B}$-doping in $\mathrm{g}-\mathrm{C}_{3} \mathrm{~N}_{4}$ is to decrease the $\mathrm{HOMO}$ energy, thus, increasing the oxidation strength of $\mathrm{g}-\mathrm{C}_{3} \mathrm{~N}_{4}$. 
Defective graphenes can also promote the oxidative degradation of $\mathrm{C}=\mathrm{C}$ in conjugated alkenes (67). The selectivity of the reaction clearly changes depending on the conversion, being benzaldehyde formed as primary product. Benzaldehyde can appear by superoxide attack to electron rich conjugated alkenes. Thus, the reaction mechanism in this case seems to be of Type II in which electron transfer to oxygen forming the superoxide is the key step in the mechanism.

For Type I oxidation mechanism, centers that are able to stabilize radicals are presumably the active sites and they should be related to carbon atoms with imperfect valence or to the presence of heteroatoms. For oxidation mechanisms related with Type II, redox centers able to transfer electron density to molecular oxygen are believed to be required, e.g. through oxygen physisorption. Alternatively we believe that charge transfer complexes between electron rich organic substrates and the electron deficient dioxygen are more suitable. Considering the importance of aerobic oxidations in the synthesis of bulk chemicals, (69) it is clear that further model experiments with new functional, site-enriched carbon materials to clarify the nature of the active centres are needed.

Besides dioxygen, activation of hydrogen peroxide is also considered as an environmentally-friendly oxidation, with $\mathrm{H}_{2} \mathrm{O}$ as the side product. $\mathrm{H}_{2} \mathrm{O}_{2}$ activation also takes place by electron transfer (70). The first electron transfer is the base of Fenton-like reactions that are in general terms efficient advanced oxidation processes and, for instance, currently used in final water decarbonization. Advanced oxidations can effectively degrade and eventually mineralize organic compounds in aqueous environments.

Current drawbacks hampering the wide application of this process are: the need of acidic $\mathrm{pH}(\sim 3)$ to achieve appropriate $\mathrm{Fe}^{2+}$ speciation; the high $\mathrm{H}_{2} \mathrm{O}_{2}$ consumption due to the parallel disproportionation to $\mathrm{H}_{2} \mathrm{O}$ and $\mathrm{O}_{2}$, as well as the stoichiometric consumption of transition 
metal leading to the formation of sludges. In order to overcome at least some of these limitations, heterogeneous catalytic Fenton reactions based on the use of sub-stoichiometric amounts of metals, metal oxides, aluminosilicates, but also nanocarbons have been considered as an alternative. $(71,72)$ In this context, Garcia and co-workers have proposed that hydroquinone/quinone-like functional groups of carbonaceous materials can act as catalytic sites.(73) The order of activity of the diverse carbon materials analysed for phenol degradation and $\mathrm{H}_{2} \mathrm{O}_{2}$ decomposition is $\mathrm{G} \sim \mathrm{rGO}>(\mathrm{B}) \mathrm{G}>(\mathrm{B}, \mathrm{N}) \mathrm{G}>(\mathrm{N}) \mathrm{G}>\mathrm{GO}$, while no activity was found in the absence of catalyst.(73) The most active "G" catalyst was derived from pyrolysis of alginate, having an oxygen content of $8 \mathrm{wt} \%$. The total oxygen content did not correlate in this case with the observed catalytic activity. In the case of the specific N-doped carbon analysed in this work, $\mathrm{H}_{2} \mathrm{O}_{2}$ decomposed at much higher reaction rates than phenol disappears, i.e. this material catalysed the disproportionation of the peroxide derivative. In the case of (B)G an induction period was observed for phenol degradation, but not for $\mathrm{H}_{2} \mathrm{O}_{2}$ decomposition. This induction period characterized by $\mathrm{H}_{2} \mathrm{O}_{2}$ consumption was correlated with the observation of boron leaching from the solid material to the solution as revealed by ICP measurements. Importantly, the possible contribution of metal traces present in rGO for the observed was ruled out by performing additional catalytic experiments with purposely added $\mathrm{Mn}^{2+}$. DFT calculations and the use of simple molecules as organocatalysts suggest that hydroquinone/quinone-like moieties are presumably the active sites for the decomposition of $\mathrm{H}_{2} \mathrm{O}_{2}$ to $\mathrm{HO}$ radicals. Enhanced catalytic activity was achieved by using hydroquinone substituted with electron donating groups such as $-\mathrm{OCH}_{3}$ or $-\mathrm{CH}_{3}$.

Graphene-based edges with quinone-hydroquinone structure are thereby able to act similarly to the $\mathrm{Fe}^{2+} / \mathrm{Fe}^{3+}$ redox pair $(0.77 \mathrm{~V})$. Accordingly, electron and oxygen-rich domains in carbonaceous materials alike to hydroquinone would give one electron to $\mathrm{H}_{2} \mathrm{O}_{2}$ forming the super-reactive hydroxyl radical that would attack pollutants present in water. The 
hydroquinone centre will be restored by a second $\mathrm{H}_{2} \mathrm{O}_{2}$ molecule acting in this case as reductant. The mechanistic cycle is indicated in Scheme .
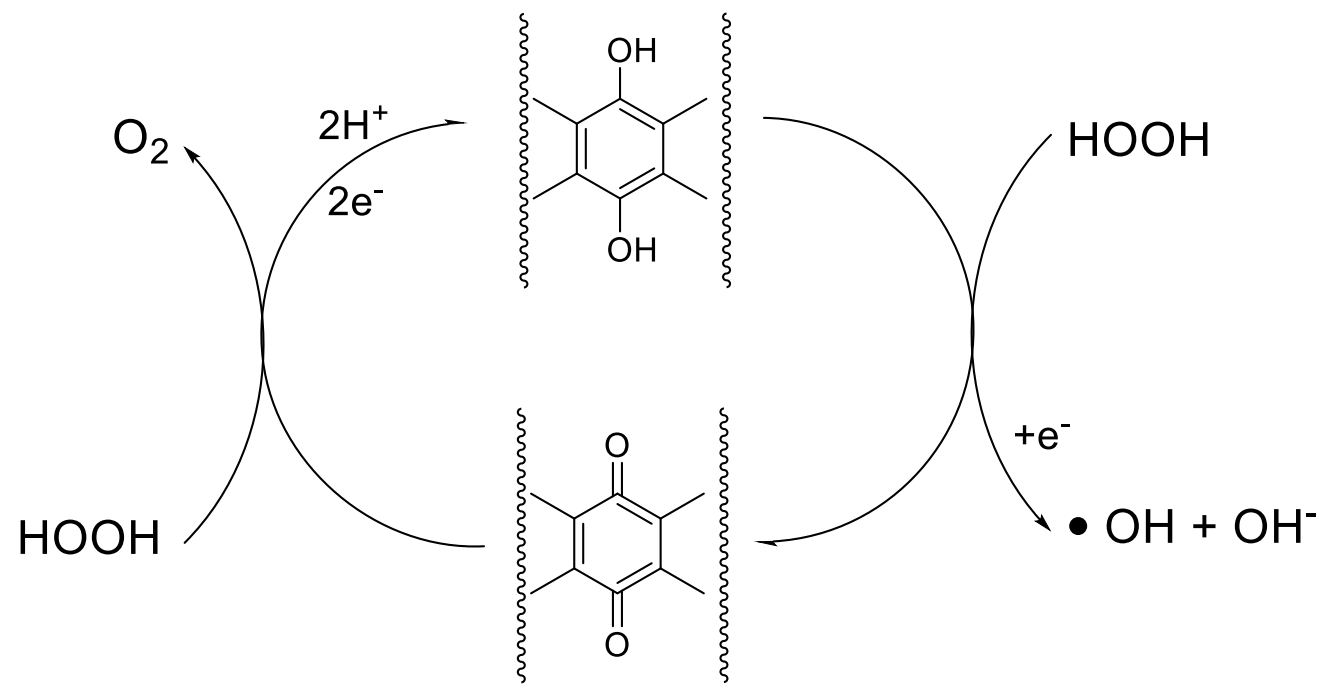

Scheme 4. Proposed sites for the generation of $\mathrm{HO}$ radicals from $\mathrm{H}_{2} \mathrm{O}_{2}$ by defective graphenes.

Recently, rGO has also been employed to catalyze the decomposition of $\mathrm{p}$ hydroxybenzoic acid as model pollutant by ozone in water (74). It was found that rGO promotes the $\mathrm{O}_{3}$ decomposition to ${ }^{\circ} \mathrm{O}_{2}{ }^{-}$and ${ }^{1} \mathrm{O}_{2}$ as evidenced by EPR measurements as well as selective quenching experiments. The catalytic activity of rGO was higher than that of acidic active carbon (AC) or GO. Catalyst deactivation occurs due to the oxidation of the rGO surface, although a thermal treatment of the used rGO catalyst could restore completely the catalytic activity.

Boron and fluorine doped mesoporous carbon nitride (CNBF) prepared using 1-butyl-3methylimidazolium tetrafluoroborate as template is a very strong oxidation catalyst and can catalyse even cyclohexane oxidation by $\mathrm{H}_{2} \mathrm{O}_{2}$.(75) Indeed, this material can be considered "carbonaceous", as its electronic properties after condensation are rather different to blank carbon nitride, e.g. the material is black. Although blank $\mathrm{g}_{-} \mathrm{C}_{3} \mathrm{~N}_{4}$ also exhibits some activity, 
the presence of boron and fluoride in $\mathrm{C}_{3} \mathrm{~N}_{4}$ increases both conversion and the selectivity of $\mathrm{H}_{2} \mathrm{O}_{2}$ decomposition towards the oxidation. The key point in the preparation of CNBF is the use of an imidazolium ionic liquid to assist polycondensation. The resulting B,F,N-codoped framework experiences an expansion of the interlayer distance and a sponge-like mesopore structure with dimensions of about $9.5 \mathrm{~nm}$ and surface area that can be as high as $444 \mathrm{~m}^{2} / \mathrm{g}$. XPS indicates a high boron content of about $20 \mathrm{~mol} \%$ and much lower fluorine content of 4 mol\% due probably to fluorine saturated residual bonds, the boron site is presumably the place of $\mathrm{H}_{2} \mathrm{O}_{2}$ binding and electron transfer. The CNBF materials appear to be highly selective oxidation catalyst, particularly for the mono-oxidation to cyclohexanone and do not produce adipic or valeric acids under these conditions. Moreover, the CNBF catalysts show high stability and can be reused without decrease in the catalytic activity.

The use of GO with TEMPO as a co-reactant has been reported for the selective oxidation of 5-hydroxymethylfurfural (HMF) to 2,5-diformylfuran (DFF) with 100\% HMF conversion with $99.6 \%$ selectivity to DFF using $80 \mathrm{wt} \%$ GO loading at 1 atm air pressure. (76) As the active site a structure formed by a carboxylic acid group and free radicals located at edges was proposed. A series of model compounds with various oxygen functional groups like hydroxyl, carbonyl, anhydride, and carboxyl groups were tested in the presence of TEMPO, and the activity increased in the order: acetic acid $\sim$ hexanoic acid $<$ benzoic acid $<1$-pyrene carboxylic acid « GO. The data with model compounds demonstrate that already the carboxylic acid-TEMPO system has always a weak intrinsic activity for the aerobic oxidation of HMF while the large $\pi$-conjugation system of a connected conjugated carbon system leads to a significantly enhanced catalytic activity.

\section{Metal-free carbonaceous materials in reductions}


Another base operation in catalysis with large synthetic and industrial importance is hydrogenation.(77) Hydrogenations are usually promoted by costly noble metals such as Pt, Ir, $\mathrm{Rh}$ and $\mathrm{Pd}$ and, for the sake of sustainability but also sheer economy, there is much interest in finding alternative catalysts for this reaction type. Hydrogenations were once considered to be promoted exclusively by transition metals, but Stephan in the 90s developed a new concept for organocatalytic, metal-free, hydrogen activation that has appeared to be generally applicable also for carbon solid. It was found that the presence of "frustrated Lewis acid-base pairs" (FLP) can promote $\mathrm{H}-\mathrm{H}$ bond cleavage in a heterolytic fashion (Figure 5a). The key issue is to have an acid (able to bind to the hydride) and a base (able to bind the proton) sufficiently close in distance to interact with an $\mathrm{H}-\mathrm{H}$ molecule but without undergoing collapse by reacting by themselves. Error! Reference source not found. illustrates the frustrated Lewis acid base pair concept for $\mathrm{H}_{2}$ activation.

In carbocatalysts, dopant elements such as $\mathrm{B}, \mathrm{N}$ or $\mathrm{P}$ can act as Lewis acid or base centres. Nitrogen and oxygen lone electron pairs can be basic. Again, defects in carbon materials can promote basic and acid nature even of conjugated carbon structures, e.g. a highly positive charge localization point in $\mathrm{C}-\mathrm{C}$ conjugation will always act as a hydride acceptor site.(79) Therefore, all these types of carbon materials can in principle act as hydrogenation catalysts. For the formation of FLP, also the stacked layered structure might be great relevance as two neighbouring layers may terminate with an acid-base pair being stabilized in such a way that they are in the right distance for an FLP to be operative, i.e. between $0.33-0.36 \mathrm{~nm}$ stacking height (Figure 5b). Concerning nucleophilicity, DFT calculations have revealed that the carbonyl oxygen of quinone-like groups is the most nucleophilic site compared to the other oxygen atoms, such as carboxyl, 1,2- and 1,3diketones, isolated ketones or lactones (80). $\mathrm{Ag}^{+}$-binding energy calculations were employed 
to establish theoretically the relative oxygen nucleophilicity order based on electron density parameters. The best coordinating center is in fact a diketone in zig-zag configuration.

Theoretical models support that a graphene bilayer and graphene ribbons having boron and nitrogen as dopant elements should be effective frustrated Lewis pair catalysts for activation of molecular hydrogen (81) Analysis of the structures along the reaction path suggest that the hydrogen molecule is heterolytically dissociated. The reaction occurs asynchronous as one of the hydrogen atoms interacts initially with the active site followed by the other one. According to this model, it would be most favourable to synthesize a carbon structure with separated boron and nitrogen moieties in different carbon sheets in order to act as FLPs. This already points to the discussion that carbon materials are more than molecules, but packed solid state structures and that a catalytic site can extend over more than one layer and involves the electronic environment of a number of separated units. Indeed, especially simultaneous acid-base interactions, charge or bond frustration or bipolar charge-transfer activation work much better "over the layers" on the edges of carbon nanostructures.

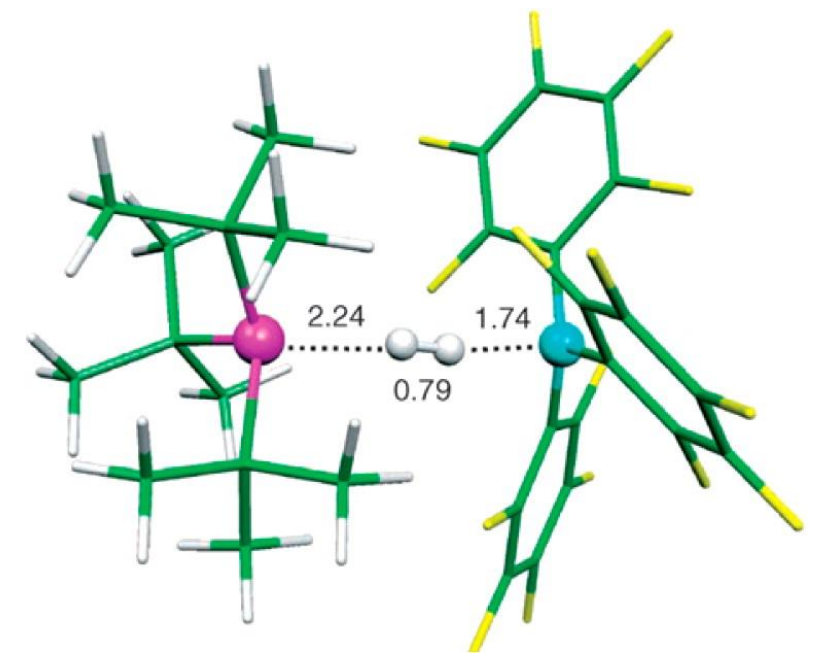



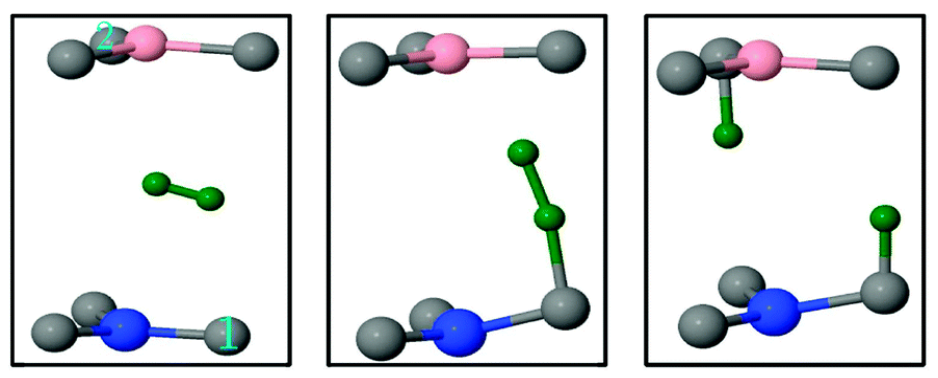

Figure 5. a) FLP "encounter complex" between $\mathrm{tBu}_{3} \mathrm{P}$ and $\mathrm{B}\left(\mathrm{C}_{6} \mathrm{~F}_{5}\right)_{3}$ binding to hydrogen. (taken with permission from (143)), b) Energetically minimized potential reaction path for the activation of hydrogen in a B-N-codoped carbon bilayer as a possible solid state FLP site. Note that the hydrogen first binds to adjacent carbon atom beside the nitrogen, with the $\mathrm{H}-\mathrm{H}$ bond of this complex significantly extended. Color code: boron is pink, nitrogen is blue (taken with permission from ref. 81).

It has been reported that $\mathrm{r}-\mathrm{GO}$ and related defective graphenes can not only act as catalyst for the liquid phase hydrogenation of alkenes but also they can catalyse the selective hydrogenation of alkynes in the presence of a large excess of alkenes in the gas phase (82). This reaction has considerable importance in petrochemical industry for the purification of cracking streams, in where the presence of acetylene, even in small amounts, is highly detrimental for the polymerization of ethylene. The selective conversion of acetylene can be promoted by a carbocatalyst obtained from pyrolysis of alginate at $900{ }^{\circ} \mathrm{C}$ followed by exfoliation of the graphitic carbon residue. The activity of this material increases upon increasing the reaction temperature, reaching an optimal value of $99 \%$ of acetylene conversion with only $21 \%$ conversion of ethylene at $120^{\circ} \mathrm{C}$.

It was proposed that the activation of $\mathrm{H}_{2}$ on graphitic carbons also takes place via an FLP mechanism, resulting in the simultaneous formation of $\mathrm{H}^{+}$-like and $\mathrm{H}^{-}$-like sites. This claim was supported by preadsorbing $\mathrm{D}_{2}$ on the catalyst, followed by evacuation and subsequent 
heating on a $\mathrm{H}_{2}$ stream, whereby the detection of $\mathrm{H}-\mathrm{D}$ by mass spectrometry confirmed $\mathrm{H}_{2}$ activation by isotopic H-D scrambling. Control experiments in where acetylene conversion was found to depend on the presence of $\mathrm{CO}_{2}$ (increasing conversion by $33 \%$ ) or $\mathrm{NH}_{3}$ (decreasing conversion by $9 \%$ ) in the stream also point to the role of acidic and basic sites for the process. These gas effects modifying the acid-base character were reversible, and the catalytic activity was recovered to the initial state when removing $\mathrm{CO}_{2}$ or $\mathrm{NH}_{3}$.

Carbon materials can also hydrogenate other multiple $\mathrm{C}=\mathrm{X}$, and $\mathrm{X}=\mathrm{Y}$ bonds. One example that is used in industry in large scale is hydrogenation of nitro groups to amines that can also be carried out by reduced graphenes and defective graphenes (83). The already discussed "performance product" obtained by pyrolysis of alginate at $900{ }^{\circ} \mathrm{C}$ under inert atmosphere also works for the reduction of nitro to the corresponding amino compounds, using hydrogen as a reducing agent (84). Nitro reduction however will be discussed also below in context with charge transfer catalysis.

Hydrothermally treated graphene oxide (HGO) was found to be a new metal free catalyst for the activation $\mathrm{NaBH}_{4}$, here exemplified by the reduction of 4-nitrophenol to 4aminophenol (85). The increase of the reactivity of metal hydrides derives from the polarization of the metal-hydrogen bond along the functional carbon surface. Combined experimental and theoretical investigations revealed that using $\mathrm{NaBH}_{4}$ as reducing agent, both acidic hydroxyl groups as well as pores are active, and one might speculate that also here FLPs may also contribute to bond polarization.

\section{Metal-free carbonaceous materials for simultaneous oxidation/reduction processes,}

The concept to run a catalytic "redox" cycle, either by chemo-, electro-, or photocatalysis relies on the existence of stable redox states in a material which can be activated at 
appropriate stages of reaction where additional oxidation or reduction power would help, with the whole cycle of course reconstituting the original state. It is clear that graphite as such is rather not in this business, as it is semi-metallic and without localized charge states. However, highly functionalized carbonaceous materials are suitable, and in the very end we need only donor and acceptor structures within the carbon framework

A number of papers indeed described that also carbon nanostructures can turn into active photocatalysts for organosynthesis. A recently published minireview lists indeed oxidation of alcohols, epoxidation of alkenes, hydroxylation of phenols, and photoreduction of $\mathrm{CO}_{2}$ as already documented cases (86). Absorbing materials as black carbons can in addition act as photosensitizers, as a local photothermal heat source, but also as an active, non-innocent support for other photocatalysts, e.g. organic dyes or titania.

Another rather open field is the so called carbon quantum dots (CQDs). Many of them show pronounced blue or white fluorescence (87-90), i.e. they are able to generate a high energy electron-hole pair. That means that also (photo)redox catalysis is possible. This of course is in apparent contradiction with a semi-metallic character and a Fermi-level close to the standard hydrogen potential. CQDs might therefore be chemically very different to the expectations of pure carbon structures, and indeed, many of them contain only about $60 \mathrm{wt} \%$ of carbon, i.e. they are rather functional, conjugated, polymeric resins than carbons.

An easy option to explain the optical and chemical reactivity of CQDs is the presence of organic donor and acceptor functionality, potentially located in separated parts of the CQD, e.g. as a core-shell heterojunction structure. Then the fluorescence would come from the recombination of charges located at the functional surface and carbon core, and the surface could show chemical reactivity. We indeed believe that such structures can be very powerful (photo)catalysts and are able to act as synthetic enzyme-like nanostructures but their branding 
as "CQD" is a little misleading as it suggests to material scientists a potentially wrong chemical structure and wrong physical behaviour.

Going to heavily doped systems, it is well known that the introduction of massive heteroatom inclusion opens up band-gaps and turns the resulting materials into semiconductors with redox properties. This is true for both irregular and regular structures, and the model cases of (regular) $\mathrm{C}_{3} \mathrm{~N}$ (band gap 0.39 Volts, a ferromagnet when doped (91)), $\mathrm{C}_{2} \mathrm{~N}$ (band gap $1.96 \mathrm{~V}(92,93)$ ), or the most prominent $\mathrm{C}_{3} \mathrm{~N}_{4} . \mathrm{C}_{3} \mathrm{~N}_{4}$ is strongly yellow and has a semiconductor-like optical adsorption extending into the visible range with an onset at 460 $\mathrm{nm}$, corresponding to an optical band gap about $2.7 \mathrm{eV}$. The ability of $\mathrm{C}_{3} \mathrm{~N}_{4}$ to oxidize and reduce is dictated by the potentials of the conduction band (minimum energy of $-1.3 \mathrm{~V}$ at $\mathrm{pH}=7$ ) and the valence band (maximum for reduction and oxidation, $1.4 \mathrm{~V}$ at $\mathrm{pH}=7$ ), respectively (94). The chemical reactivity of heterogeneous, metal-free carbon nitride materials have been described in a number of prominent reviews $(95,96)$ and just serves in the present context as an inspiration for related carbon structures.

For all other highly heteroatom doped carbon materials, the next step for simultaneous oxidation and reduction is the ability to tune the HOMO-LUMO energy potentials of the specific material to adapt them to the optimal value to promote oxidation (by the positive holes) or for reduction activation (by the conduction band electrons). The available data shows that this tuning can be achieved in several alternative ways, including doping, structural changes in the material and the formation of strong association complexes between small organic molecules and the carbon materials which then even start to organize to superstructures and create functional pores (see for instance Error! Reference source not found.). These small molecules can donate or withdraw electron density from the 
carbocatalysts and, in this way, alter the work function of the material $(97,98)$, finally even creating complex polarity and functionality patterns.

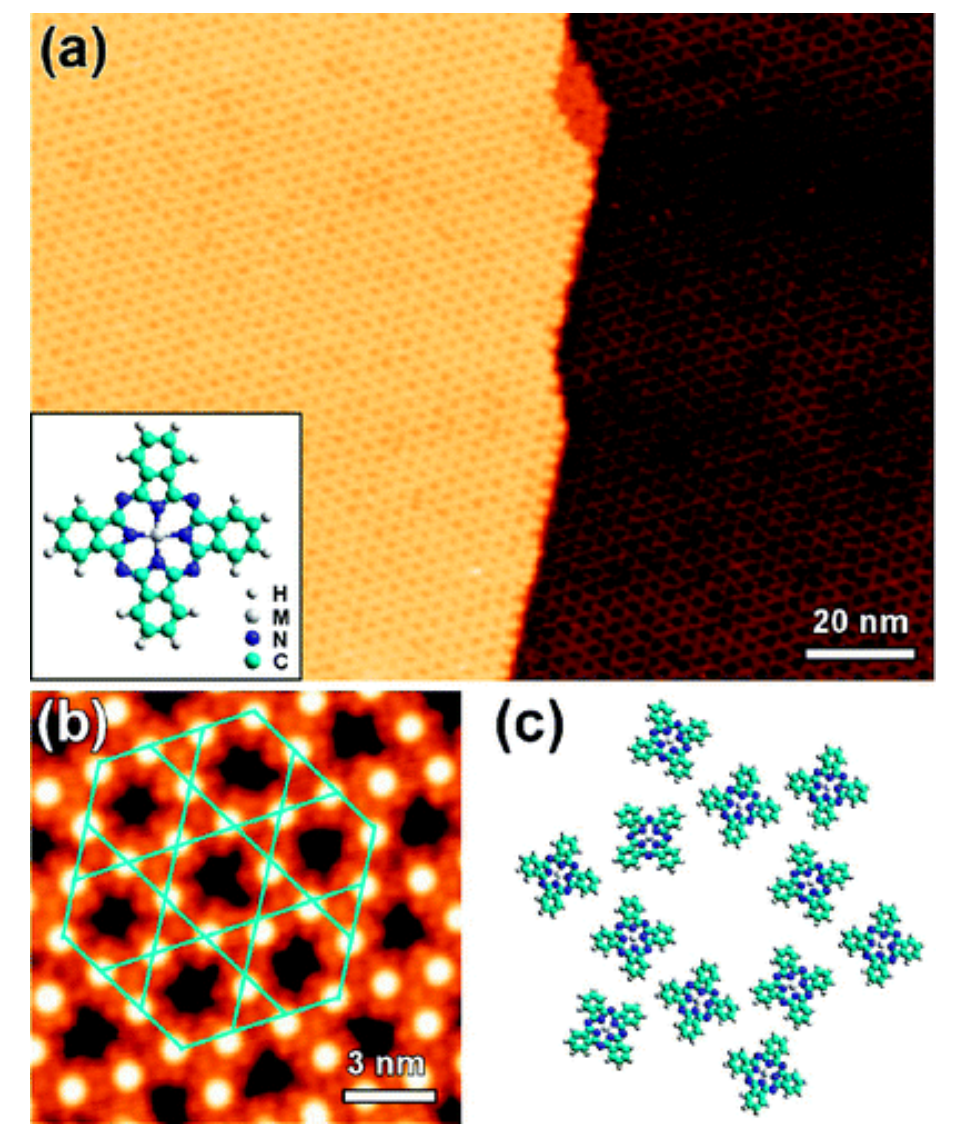

Figure 6. STM images obtained after RT deposition of Fe-Phthalocyanine (Pc) on Rusupported monolayer graphene (a) Overview image showing identical orientations of the Kagome lattice of FePc. The structural model of Pc is shown in the inset. (b) Details of the Kagome lattice of FePc. A trihexagonal tiling is highlighted. The unit cell of the Kagome lattice is marked with blue lines. (c) Structural model of the Kagome lattice showing molecular orientation disorder. (taken with permission from ref 141)

Besides this adaptation of the frontier orbital energies, selectivity of the reaction towards a single product would require the design of the geometry and dimensions of the reaction cavities surrounding the active centres, resembling as much as possible the centres in 
enzymes. This requires the jump from flat $2 \mathrm{D}$ surfaces to tectonic $3 \mathrm{~d}$-carbon materials with pores with the required dimensions, adsorption-polarity properties, etc. In this way, by combining the energy levels of the material and shape of the reaction cavity, metal-free catalysts with high activity and exquisite selectivity are expected.

\section{Catalysis involving charge transfer complexes with the substrate}

For covalent conjugated materials, the adjustment of electroaffinity or work function opens the exiting possibility of enabling a new type of reaction activation. Charge-transfer complexes are well known, especially between electron-rich and electron-poor aromatic systems, such as in the famous model case chinhydron discovered by Wöhler in 1844 (99). As electron rich, nucleophilic species bind strongly to electron poor, electrophilic species, this can be understood as the third type of acid/base activation (beside the Bronsted and the Lewis principle). It was already mentioned that contrary to general knowledge, the work function of carbonaceous materials can be varied by heteroatom doping over a rather broad range, potentially between $-0.5-2.0$ Volts! This covers the electrochemical range from lead to gold, i.e. a rather wide range of nobility. The concept of noble carbons was summarized in a recent review, and indeed, some of these carbons are even able to take electron density from metallic gold (97).

Adding now an electron rich substrate to such a noble carbon will result in spontaneous charge transfer or "acid-base-interaction", with 2 Volts difference in electroaffinity translating in ca $200 \mathrm{~kJ} / \mathrm{mol}$ binding strength, i.e. an interaction that is stronger than most classical acid-base interactions (sufficient difference in electroaffinity assumed).

To interact and bind acidic substrates, the corresponding carbons should be rather electron rich, such as freshly reduced rGO or the products of other carbonization recipes 
prepared under highly reductive conditions. It was already stated above that such carbons are commonplaces in adsorption science, known to bind acidic impurities such as $\mathrm{HCl}$ from the gas phase or hydronium ions from water.

Selective reduction of nitroarenes to the corresponding anilines is known to be catalyzed by natural graphite (100), fullerene (101), and rGO (102), i.e. all electron-rich carbons. Recently, the role of different oxygen functional groups on a carbon catalyst in this reduction of nitrobenzene by hydrazine has been studied using a series of model molecules (103). It was observed that the carbonyl and hydroxyl groups are the most likely centers in the activation of hydrazine as reducing molecule. It was found that already the use of 9,10anthraquinone as a low molecular weight model catalyst for the corresponding carbons affords $97.7 \%$ conversion with $98.4 \%$ selectivity to aniline, and a charge transfer activation between the electron poor nitroarenes and anthrachinon can be assumed. The reduction of nitrobenzene by 9,10 -anthraquinone occurs both under helium atmosphere as well as in air, which suggests that the active hydrogen resulting from hydrazine decomposition is the real reducing species. It is believed that the reduction of nitrobenzene can take place either through direct or through condensation pathways (104). In the direct pathway, nitrobenzene is reduced to nitrosobenzene, hydroxylamine, and aniline, successively, whereas through the condensation pathway, nitrosobenzene reacts with hydroxylamine to form azoxybenzene, which is further reduced to azobenzene, hydrazobenzene, and aniline. A series of control experiments revealed that the most likely mechanism when using 9,10-anthaquinone as catalyst proceeds via the direct route.

In this framework of a generalized acid-base model, not only aromatic compounds, but also gases as $\mathrm{CO}_{2}, \mathrm{O}_{2}$, or even $\mathrm{H}_{2}$ can be activated, as long as electron density is moved from the material to the substrate. As in case of acid sorption, the charge transfer can be quantified 
by the increase of adsorption enthalpy beyond usual van der Waals values (as they can revealed from inert adsorbents).

A very special case is again carbon nitride with its rather positive HOMO position of + 1.4 Volt. Nitrogen containing materials are in general good adsorbents for $\mathrm{CO}_{2}$ due to the assumed formation of a carbamate intermediate (105). However, the $\mathrm{CO}_{2}$ bound to electrophilic supports shows a special reactivity, as expressed when adding benzene. While adenine-coated mesoporous oxides spontaneously allow the formation of benzoic acid through a Friedel-Crafts type addition (106), the predominant product in the case of mpg$\mathrm{C}_{3} \mathrm{~N}_{4}$ is phenol, accompanied by biphenyl as by-product.(107) The reaction occurs with evolution of $\mathrm{CO}$ and, i.e. the $\mathrm{CO}_{2}$ molecule is polarized at the surface (see (see Figure ). DFT calculations suggest that the key step in the reaction mechanism leading to phenol is the $2+2$ cycloaddition of the $\mathrm{C}-\mathrm{H}$ bond of adsorbed benzene onto the activated and polarized $\mathrm{C}=\mathrm{O}$ bond.

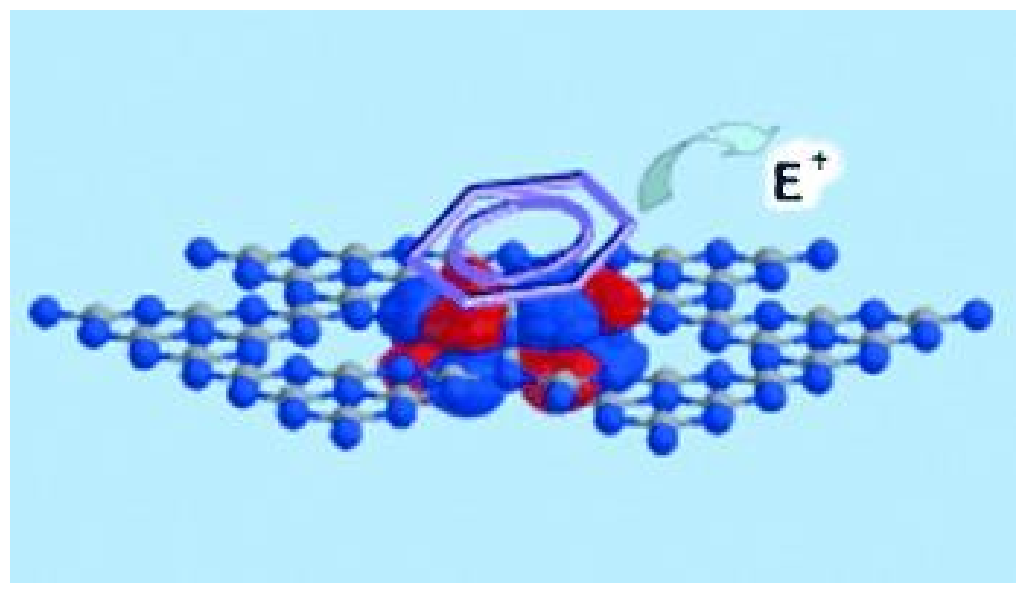

Figure 7. HOMO level of melem unit of $\mathrm{g}-\mathrm{C}_{3} \mathrm{~N}_{4}$ is the one interacting with benzene pi-cloud favouring CT and subsequent Friedel-Craft reaction. (Taken with permission form Ref. 106)

Another remarkable clear case for graphitic carbon nitrides was reported in FriedelCrafts-catalysis.(108) Here, electron transfer from the benzene to graphitic carbon nitride 
does the same role as a solid acid catalyst, and benzene could be successfully activated to be alkylated by methanol or substituted by cyano groups using urea as a transfer agent. Similar arguments hold true for the catalyzed trimerization of nitriles and acetylenes (109) which were also shown to be driven by charge transfer interactions of the nitriles with the graphitic basal planes of the catalyst.

Another exciting reaction which proves CT-activation of the substrates for a reaction where otherwise noble metals were considered to be mandatory are aromatic carbon-carbon coupling reactions. Recently, reduced $\mathrm{GO}$ in combination with $\mathrm{KO}^{\mathrm{t}} \mathrm{Bu}$ has been employed as an efficient heterogeneous catalyst for the direct $\mathrm{C}-\mathrm{H}$ arylation of benzene by iodobenzene to biphenyl (110). This is related to the classical Suzuki-Miyaura cross coupling reaction catalyzed by Pd. In the present case, it was found that manganese or iron impurities do not play any role. The electron rich graphitic $\pi$ system greatly favoured the reaction by adsorbing the aromatic reagents before coupling by CT-complex formation. The stabilizing and activating effect of $\mathrm{K}^{+}$ions was proposed to facilitate the activation of the C-I bond of $\mathrm{C}_{6} \mathrm{H}_{5}-\mathrm{I}$ after adsorption, which in our view helps to stabilize the negative charge transfer to the reagents. The importance of $\mathrm{K}^{+}$was further supported by performing a reaction in the presence of 18-crown- 6 to trap the $\mathrm{K}^{+}$ions, observing that the $\mathrm{C}-\mathrm{H}$ arylation of benzene with 4-iodoanisole was effectively stopped.

\section{Carbon-Carbon and Carbon-Nitrogen coupling catalyzed by carbonaceous materials}

Expanding on C-C coupling reactions, recently a general strategy for alkylation of arenes with styrenes and benzylic alcohols catalyzed by GO was presented, affording valuable diarylalkanes in high yields and excellent regioselectivity (111). 
It was observed that reduced GO in suspension showed a surface area of $367 \mathrm{~m}^{2} \mathrm{~g}^{-1}$ measured by methylene blue adsorption, indicating the occurrence of partial $\pi$-stacking of the GO sheets as compared to the parental GO material $\left(1371 \mathrm{~m}^{2} \mathrm{~g}^{-1}\right)$. The increase in the $\pi$ stacking is consistent with a partial reduction of initial GO to rGO during the course of the reaction. It was proposed that the reaction mechanism of the alkylation involves activation of both coupling partners by adsorption. The key step would be activation of the olefin by hydration to an adsorbed alcohol, followed by a transition state in which the arene nucleophile is prepositioned by $\pi$-stacking interactions with the GO sheet for a concerted $\mathrm{C}-\mathrm{C}$ bond formation to give the alkylated product and regenerate the catalyst after the release of water. The classical mechanism for arene alkylation requires the presence of strong acid sites, which are not obviously present in this case. It was however already reasoned above that charge transfer interactions between the substrate and the catalyst can have a similar promotional effect as an acid, i.e. partial charge transfer from the aromatic structure to the carbocatalyst would leave a positive partial charge on the substrate which then drives the reaction. It is clear that further studies are required to provide some support to this proposed mechanism.

An efficient protocol for the formation of 2,3-dihydroquinazolinones has been reported employing GO as carbocatalyst.(112) The catalytic activity of GO is higher than that of other catalysts such as $\mathrm{PEG}-\mathrm{SO}_{3} \mathrm{H}, \mathrm{rGO} \mathrm{SnO}_{2}{ }^{-}$quantum dots, or nano $\mathrm{CuFe}_{2} \mathrm{O}_{4}$. GO retains more than $90 \%$ of its catalytic activity of the fresh sample after five uses. In addition, the presence of oxone as oxidant in the system allows expanding this cyclocondensation for the selective preparation of quinazolin-4(3H)-one derivatives.

Preadsorption on heterogeneous carbocatalysts can drive the selectivity of a reaction towards a given stereoisomer that is different to the one observed in homogeneous catalysis. 
Thus, recently, the Mukaiyama-Michael addition of 2-(trimethylsiloxy)furan (TMSOF) and 4-nitrostyrene (Error! Reference source not found.) has been reported using graphite oxide/graphene oxide-based catalyst (113). Lowering the graphite oxide loading from 12 to $0.2 \mathrm{wt} \%$ results in good yields in all cases, while the selectivity in favour of the anti diastereoisomer increases continuously. For instance, $0.2 \mathrm{wt} \%$ graphite oxide exhibited $85 \%$ yield after $6 \mathrm{~h}$ at room temperature with syn/anti ratio of 25/75. Furthermore, the use of 0.2 $\mathrm{wt} \%$ exfoliated graphite oxide further improved the yield to $90 \%$ after $6 \mathrm{~h}$ at room temperature and also the unprecedented anti selectivity up to a diastereoisomeric ratio of 23/77 (syn/anti).

DFT calculations for a graphene model was constructed by considering $54 \mathrm{C}$ atoms consisting of 19 fused six-membered rings. The geometry of the transition states indicates that the 4-nitrostyrene molecule in involved in a CT interaction with the G layer. Due to this interaction, TMSOF can attack the activated $\beta$-nitrostyrene only from the top. The main difference between the two transition states is in the relative orientation of TMSOF, which according to the calculations establishes a series of dispersive interactions (see original contribution for details). On the other hand, in the case of the uncatalyzed reaction, a favourable electrostatic interaction between the positively charged $\mathrm{SiMe}_{3}$ group and the negatively charged nitro group is the main force that drives the formation of the syn product.

\section{The material chemistry of Carbocatalysis: Nitrogen, Sulfur- and Boron doping and their codoping to construct patterned active sites}

It has already become clear in the technical cases that the inclusion of heteroatoms into the carbon structure is beneficial to adjust the overall electronic properties of a material, such as electron density and flat band potential. For instance, as judged by chemical reactivity, reduced 
graphene oxides seem to be rather electron rich, with a potential slightly negative work function, while N- or S-doped carbons are definitely rather electron poor and thereby, show a very positive HOMO level and are electrophilic. The next paragraphs will focus on publications in which heteroatoms have been used and optimized to promote carbocatalysis. Especially here, it will become clear how similar the observations and results in the two fields of metal-free electrocatalysis and chemical carbocatalysis are.

Selective aerobic oxidation of benzyl alcohol is one of the well-known model reactions where the response of a catalyst can be nicely judged in a broader context. Ndoping of graphitic carbons was for instance obtained through a high temperature (800-1000 ${ }^{\circ} \mathrm{C}$ ) nitridation (114). Among the three types of nitrogen atoms present within the graphitic framework, pyridinic $\mathrm{N}$, pyrrolic $\mathrm{N}$, and graphitic $\mathrm{N}$, the graphitic $\mathrm{sp}^{2} \mathrm{~N}$ atoms were declared to be the catalytically active centers for this aerobic oxidation. The intensity of the N1s signal can be used to determine the $\mathrm{N}$ content that decreases as the nitridation temperature increases in the order NG-800 (4.16 at $\%)>$ NG-900 (3.48 at $\%)>$ NG-1000 (1.71 at\%). The presence of $\mathrm{N}$ heteroatoms on carbocatalysts promotes benzyl alcohol oxidation with $100 \%$ selectivity to benzaldehyde by NG-900 that exhibited a ca. 4-fold enhancement in activity upon increasing the reaction temperature from 313 to $343 \mathrm{~K}$. Benzyl, p-nitrobenzyl, $p$ fluorobenzyl, $p$-methylbenzyl and $p$-methoxybenzyl alcohol could be converted, indicating the wide substrate scope of $\mathrm{N}$-doped carbons as catalysts for the aerobic oxidation of alcohols. However, the NG-900 catalyst was catalytically inactive for 1-phenylethanol.

NG-T and G samples prepared by high temperature exfoliation are believed to react with methanol to produce methoxyl radicals which were trapped by DMPO allowing to record the sextet peaks corresponding to $\mathrm{DMPO}-\mathrm{CH}_{3} \mathrm{O}$ adducts (115). Addition of benzyl alcohol decreased the EPR line intensity of DMPO- $\mathrm{CH}_{3} \mathrm{O}$, indicating that benzyl alcohol 
may be activated by the electron-deficient sites to form a benzyl radical, which competes with the generation of $\mathrm{CH}_{3} \mathrm{O}$. Adsorption of molecular oxygen over the graphitic $\mathrm{N}$ atoms to form a $\mathrm{sp}^{2} \mathrm{~N}-\mathrm{O}_{2}$ adduct transition state seems to be the elementary step leading to $\mathrm{O}_{2}$ activation. $\mathrm{No}_{2} \mathrm{O}_{2}$ was detected during the catalytic reaction.

The importance of the preparation method of $\mathrm{N}$ doped graphitic carbons and the idea of the graphitic- $\mathrm{N}$ as the active site was proposed again in another work (116). The most active $\mathrm{N}$-doped $\mathrm{G}$ sample (NG-700), obtained by reaction of $\mathrm{GO}$ and melamine and subsequent pyrolysis at $700{ }^{\circ} \mathrm{C}$, showed an enhancement of catalytic activity respect to rGO700 by a factor of 80 in oxidative phenol degradation, using peroxomonosulfate (PMS) as the terminal oxidant. NG-700 exhibited much higher activity than another sample prepared from $\mathrm{GO}$ and ammonium nitrate at $350^{\circ} \mathrm{C}$. It is important to note that using melamine as precursor a higher N-content can be obtained (NG-700, 9.68 at\%; $54.41 \%$ pyridinic, $23.09 \%$ pyrrolic and $22.49 \%$ graphitic) than by the use of ammonium nitrate (5.61 at\%) (117) annealing of GO with $\mathrm{NH}_{3}$ (3-5 at\%) (118) and CVD (5.0 at\%) (119), among others. Interestingly, the NG-700 sample is even more active than the benchmark heterogeneous $\mathrm{Co}_{3} \mathrm{O}_{4}$ catalyst and the other known carbocatalysts, e.g. SWCNTs, N doped CNT and graphene nanosheets (GNs). The proposed mechanism for PMS activation by N-G involved transfer of delocalized electrons from the zigzag edges of G to PMS. Theoretical calculations at DFT level revealed that the presence of graphitic $\mathrm{N}$ enhances the adsorption of PMS and the electron transfer to the carbon, i.e. the more electron-poor character of the N-doped carbon indeed improves the binding also of inorganic electron rich compounds.

Unfortunately, as all the previous carbon-based catalysts the NG-700 catalyst deactivates upon reuse and thermal annealing. XPS showed that the used catalyst has a higher oxygen (13.74 vs 3.11 at\%) content and lower N-doping (1.56 vs 9.68 wt\%) with respect to 
the fresh material, thus hinting to still insufficient oxygen stability of this special N-doped carbons, a fact which can be easily addressed by the introduction of even more noble carbons (97).

In line with the above commented results, $\mathrm{N}$-doping of $\mathrm{rGO}(\sim 9 \mathrm{wt} \% \mathrm{~N})$ improves the catalytic activity respect to $\mathrm{rGO}$ also for the catalytic wet air oxidation $\left(\sim 160{ }^{\circ} \mathrm{C}\right.$ at 7 bar $\left.\mathrm{O}_{2}\right)$ and catalytic ozonation (room temperature and atmospheric pressure) (120). The $\mathrm{N}$ content was assigned to pyridinic, pyrrolic and quaternary $\mathrm{N}$ atoms based on XPS. Further studies, however, about the nature of the $\mathrm{N}$-atoms that are acting as catalytic sites in these oxidation processes are still needed.

$\mathrm{N}$-doped graphitic carbons have been reported also as a metal-free catalyst for the reduction of 4-nitrophenol to 4-aminophenol using $\mathrm{NaBH}_{4}$.(121) The carbocatalyst exhibited a pseudo zero order kinetics, that was found different from pseudo first order reactions catalyzed by metal NPs (122). Evidence was obtained to consider adsorption of 4-nitrophenol as the decisive elementary step responsible for the pseudo zero order kinetics. Theoretical studies, on the other hand, suggested that carbon atoms bonded to $\mathrm{N}$ atoms are activated and exhibit favourable charge density to bind the substrate. The N-doped carbon material showed good adsorption capability for 4-nitrophenol, thus activating the nitrophenol for reduction by the adsorption process.

Co-doping with two or more dopant elements, especially $\mathrm{N}$ and $\mathrm{S}$, has turned into a very powerful general modification strategy $(123,124)$ and enlarges the potential to tune electronic structure and the catalytic activity of this material. For activation of the already discussed PMS, it has been observed that co-doping with S (0.69\%) and N (8.15\%) causes a synergism for oxidant activation (125). The low $\mathrm{S}$ content respect to $\mathrm{N}$ was attributed to the larger difference in atomic diameter 1.03 and $0.71 \AA$, however with other doping strategies 
we find partly very high sulfur contents (142). The $\mathrm{N}$ content was mainly distributed in pyridine-like (39.8\%), pyrrole-like (51.6) and quaternary nitrogen (8.6 \%) according to XPS. The sulfur content was assigned to C-S-C and C-SOX-C. DFT calculations of models for G, S-G, N-G, S-N-G and S-S-N-G were carried out to get some insights into the effect of dopants on the electronic structure in a graphitic model (see Figure 8). In the case of S-doped $\mathrm{G}$ insignificant charge transfer was described, while $\mathrm{N}$ doping induces a positive charge density on the adjacent carbons (C1, C2 and C3). Simultaneous co-doping with N and S of G sheet further increases the positive charge density at carbon $\mathrm{C} 2$ from 0.31 to 0.48 . Thus, a good correlation between polarization of electron density by the dopant elements and the experimental catalytic activity for PMS decomposition was observed. Unfortunately, also this special SN-rGO deactivates upon use, and its catalytic activity could not be recovered. Further synthetic refinements are therefore needed to increase the stability of codoped NScarbons to enable reusability of the materials.

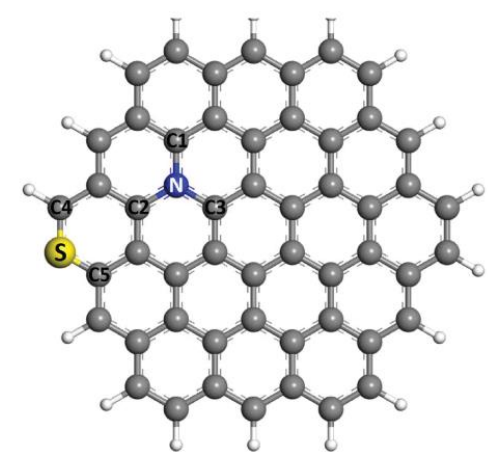

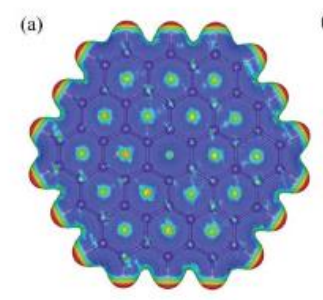

(d)

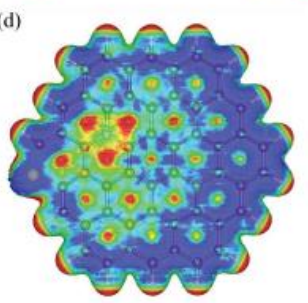

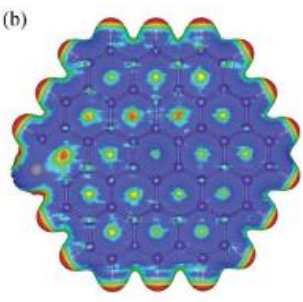

(e)
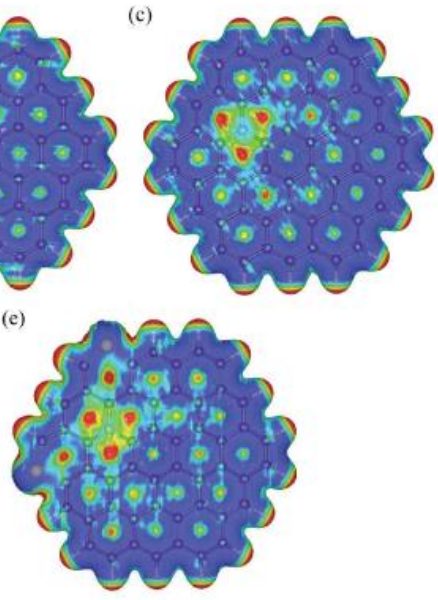

Figure 8:. Molecular model of S-, N-dual doped graphene and electrostatic potential mapping form charge density matrix for a) undoped model graphene, b) S-G, c) N-G, d) S-NG, and e) S-S-N-G. (Taken with permission from Ref. 125) 
The activity of nitrogen and boron co-doped graphene (B,N-G) was tested for acetylene hydrochlorination (126). XPS and Raman spectroscopy proved that N and B atoms are covalently doped into the $\mathrm{G}$ sheets. Under the same reaction conditions, the initial acetylene conversion for GO, B-G, N-G, and B,N-G catalysts follows the order B,N-G > N-G $>$ B-G $>$ GO. The estimated TOF values for N-G and B,N-G catalysts were $8.33 \times 10^{-3} \mathrm{~min}^{-1}$ and $3.32 \times 10^{-2} \mathrm{~min}^{-1}$, respectively, indicating the benefits of co-doping into graphic carbon. These TOF values are higher than that of the $\mathrm{SiC} @ \mathrm{~N}-\mathrm{C}$ composite reported before $\left(\sim 5.63 \times 10^{-3} \mathrm{~min}^{-1}\right)(127)$ and also higher than that of $\mathrm{C}_{3} \mathrm{~N}_{4}\left(1.42 \times 10^{-2} \mathrm{~min}^{-1}\right)$ (128). The TOF values for the two most active catalyst with metal coordination, namely $\mathrm{Au} / \mathrm{AC}$ and $\mathrm{Hg} / \mathrm{AC}$, are 5.38 and $0.22 \mathrm{~min}^{-1}$, respectively. ${ }^{1}$ Hence, the catalytic performance of $\mathrm{B}, \mathrm{N}-\mathrm{G}$ is significant, but still not competitive with the best metals. Both experimental and theoretical studies suggest that the carbon atoms bonded to $\mathrm{N}$ species are the active sites. The enhanced activity of B,N-G $(10.96 \% \mathrm{~N} ; 15.47 \% \mathrm{~B})$ may be due to its higher $\mathrm{N}$ content compared with $\mathrm{N}-\mathrm{G}(5.47 \% \mathrm{~N})$. Also, the presence of $\mathrm{B}$ atoms changes the electronic density of the $\mathrm{N}$ atom and, therefore, influence $\mathrm{HCl}$ adsorption on the $\mathrm{N}$ active sites. Adsorption of $\mathrm{HCl}$ on the Gcatalyst is the rate-determining step of the acetylene hydrochlorination. In the matrix of B,N$\mathrm{G}$, carbon atoms act as the adsorbing site for $\mathrm{C}_{2} \mathrm{H}_{2}$, and the nitrogen atom provides the catalytic active site for $\mathrm{HCl}$ adsorption. DFT calculations anticipate that a higher $\mathrm{HCl}$ adsorption value should occur for $\mathrm{B}, \mathrm{N}-\mathrm{G}$ due to the combined interaction between pyridinic $\mathrm{N}$ and $\mathrm{B}$ atoms. In agreement with this theoretical prediction, it was measured that the presence of B increases dramatically the adsorption energy. TPD analysis showed that the binding strength of $\mathrm{HCl}$ with various $\mathrm{G}$-materials increases in the following order of $\mathrm{GO}<\mathrm{N}$ $\mathrm{G}<\mathrm{B}, \mathrm{N}-\mathrm{G}$. One of the major drawbacks of $\mathrm{B}, \mathrm{N}-\mathrm{G}$ catalyst is that acetylene conversion decreases from $94.89 \%$ to $61.88 \%$ within $4 \mathrm{~h}$ on stream, indicating its poor catalytic stability 
of the current model systems. This decay in activity was ascribed to the formation of polymerized acetylene coke around the active sites.

The simultaneous presence of $\mathrm{N}$ and $\mathrm{P}$ atoms in the corresponding graphitic carbons can also provide catalytic centers for aerobic oxidations. In this context, a simple and efficient approach was reported to synthesize P-doped graphitic porous carbon (PGc) materials by heating phytic acid in a domestic microwave oven (1100 W) for $40 \mathrm{~s}(130)$. Using this preparation methodology, it is possible to control the coordination of $\mathrm{P}$ atoms. XPS measurements indicated that the porous P-doped carbon contains 4.9 at $\% \mathrm{P}$. This porous P-doped carbon was used for the model reaction, the oxidation of benzyl alcohol, and resulted in a conversion of $33.4 \%$ at $60{ }^{\circ} \mathrm{C}$ with $>99 \%$ selectivity to benzaldehyde, which is about three times higher than the conversion achieved with a sample N-doped G under similar reaction conditions (131). Interestingly, the P-doped carbon was also active in the aerobic oxidation of 1-phenylethanol reaching $46.5 \%$ conversion with complete selectivity to acetophenone at $80{ }^{\circ} \mathrm{C}$, while in contrast the $\mathrm{N}$-doped carbon catalysts were inactive (131). It was shown that the formation of a large amount of $\mathrm{H}_{2} \mathrm{O}_{2}$ byproduct seems to be unavoidable when using noble metal based catalysts for selective oxidation of alcohols to aldehydes by molecular oxygen.(132) However, for P-doped $\mathrm{G}$ no $\mathrm{H}_{2} \mathrm{O}_{2}$ could be detected, which is another specific feature of this P-doped material compared to transition metal catalysis (133, 134). Since $P$ has the same number of valence electrons as $N$, it is believed that the mechanism of $\mathrm{O}_{2}$ activation could be similar to that calculated for $\mathrm{N}$-doped $\mathrm{G}$, involving the formation of a peroxo-like species on the heteroatom (135). XPS analysis indicated that Pdoped porous carbon contain mainly $\mathrm{P}=\mathrm{O}$ instead of $\mathrm{C}=\mathrm{O}$, whereas $\mathrm{C}-\mathrm{O}-\mathrm{C}$ groups are below the detection limit and the majority of $-\mathrm{OH}$ present on it are directly bonded to $\mathrm{P}$. Furthermore, the atomic $\mathrm{O} / \mathrm{P}$ ratio of $\sim 4$ measured by XPS for P-doped carbon suggest that 
some $\mathrm{P}$ atoms possibly connect with two or more oxygen containing functionalities, such as $\mathrm{OH}$ groups. A series of control experiments using PGc materials with similar oxygen content but different $\mathrm{P}-\mathrm{OH}$ populations suggest that the $\mathrm{P}-\mathrm{OH}$ functional groups are likely to play an important role in the oxidation. Benzyl alcohol oxidation reaction as such however did not work in the presence of molecules containing just $\mathrm{P}=\mathrm{O}$ and $\mathrm{P}-\mathrm{OH}$ functional groups, such as phytic acid and phosphorous acid. These data suggest the importance of binding of the aromatic substrate with the conjugated regions of the P-doped carbon material.

Beyond localized chemical functionality as the active site: collective solid state effects and charge transfer in catalysis

Adsorption of substrates and reagents on the graphitic carbon surfaces is generally claimed as one of the reasons of the high activity observed for graphitic carbons when compared to their reference systems ("binding precedes reaction”). Particularly, interactions of conjugated $\mathrm{sp}_{2}-$ systems with condensed polycyclic aromatic compounds, most presumably due to charge-transfer-interactions (CT) are known to be very strong, and intermolecular complexes between $\mathrm{G}$ and pyrenes have been reported, among other aromatic compounds.

We already discussed above the question on how much heterogeneous carbocatalyst can really be described by the techniques developed for molecules and how much collective properties of an electronically coupled solid state material play a role in the catalytic process. It is clear that substrate binding via charge transfer interactions, polarization transfer, or so called $\pi$ - $\pi$ - interactions will depend on the electron density of the carbocatalyst, its work function, and the higher the difference in electron density. 
The flat band potential, which corresponds to the HOMO in molecular orbital theory, is a collective property, i.e. the accessibility of electrons at a specific site depends on the electron acceptor and electron donor properties of the complete conjugated system. This is especially important for the heteroatom doping discussed above, as for instance nitrogen even far from the catalytic surface is known to make the HOMO more positive, i.e. more electron poor and thereby more "acidic"/electron accepting. Nitrogen-doped carbon made by appropriate techniques is "noble", has a metallic character, and cannot be oxidized in air even up to 700 ${ }^{\circ} \mathrm{C} .(97)$ It is a quantum-mechanical effect that electron density cannot stop at a surface, but "bends" into any other medium. This means that even acidic groups bound to such carbocatalysts will sense the altered electron density, and these acid sites on a carbon material will behave similar to molecular acids having electron pulling units: a more noble support will increase the acid strength. In that sense, controlling the electron density within a carbon framework can be regarded as the heterogeneous version of controlling electron density by ligand substitution in molecular chemistry (137): it is now in the hands of material chemistry chemist to fine-tune catalytic activity and selectivity.

\section{The Heterojunction and dyad concepts in catalysis}

A related concept coming from solid state chemistry is the concept of heterojunction. This happens when two carbocatalysts of different character are in tight contact with each other, e.g. GO@G or N-doped G@G. As the electron density cannot behave discontinuously, surface charges build up which in case of atomic or thin layers can extend over the whole sample. This means that by the right synthesis or processing, one and the same graphitic system can be brought to possess different electronegativities due to this non-covalent neighbourhood effect. This concept lies behind the unusual selective oxidation of saturated hydrocarbons by dioxygen, using a $\mathrm{C} @ \mathrm{C}_{3} \mathrm{~N}_{4}$ heterojunction (138). The classical molecular 
orbital description of this interaction is then, of course, like a charge transfer complex, where electron density is sucked into the $\pi^{*}$-orbital of the electron poor partner, thus leaving a stronger oxidizing carbocatalyst as the support phase. If molecular entities are involved, this activation was termed as "dyadic".

\section{Perspectives Carbon-Carbon heterojunctions and Fusion Materials}

Heterojunctions of different materials where there is an intimate contact between the components over a large interface may lead to the appearance of new properties different from those of the individual components. These new properties would arise from efficient charge transfer from the electron richer component to the most electronegative one. This charge transfer in the heterojunction results in a variation in the energy of the conduction and valence band of the composite respect to that of the individual components. As a result, the resulting material can be more favourable to promote (photo) catalytic reactions. One of these examples of heterojunctions is the material resulting from the combination of graphene with more electron accepting $g-\mathrm{C}_{3} \mathrm{~N}_{4}$ (139). It has been found that in the optimal proportion between the two components the resulting hybrid material has lower HOMO energy than any of the two components and a LUMO of intermediate energy between those of graphene and $\mathrm{C}_{3} \mathrm{~N}_{4}$. As consequence of the adequate $\mathrm{HOMO} / \mathrm{LUMO}$ energies, the nanocomposite can reduce oxygen to superoxide. The superoxide remains strongly bound to the surface and the positive hole generated has sufficient oxidation energy to abstract one electron from saturated hydrocarbons, particularly cyclohexane, resulting in the selective oxidation of this compound. Figure 9: illustrates how the heterojunction between the graphene and $\mathrm{g}-\mathrm{C}_{3} \mathrm{~N}_{4}$ (denoted as GSCN from graphene sheet- $\mathrm{gC}_{3} \mathrm{~N}_{4}$ ) has distinctive HOMO-LUMO energies. 


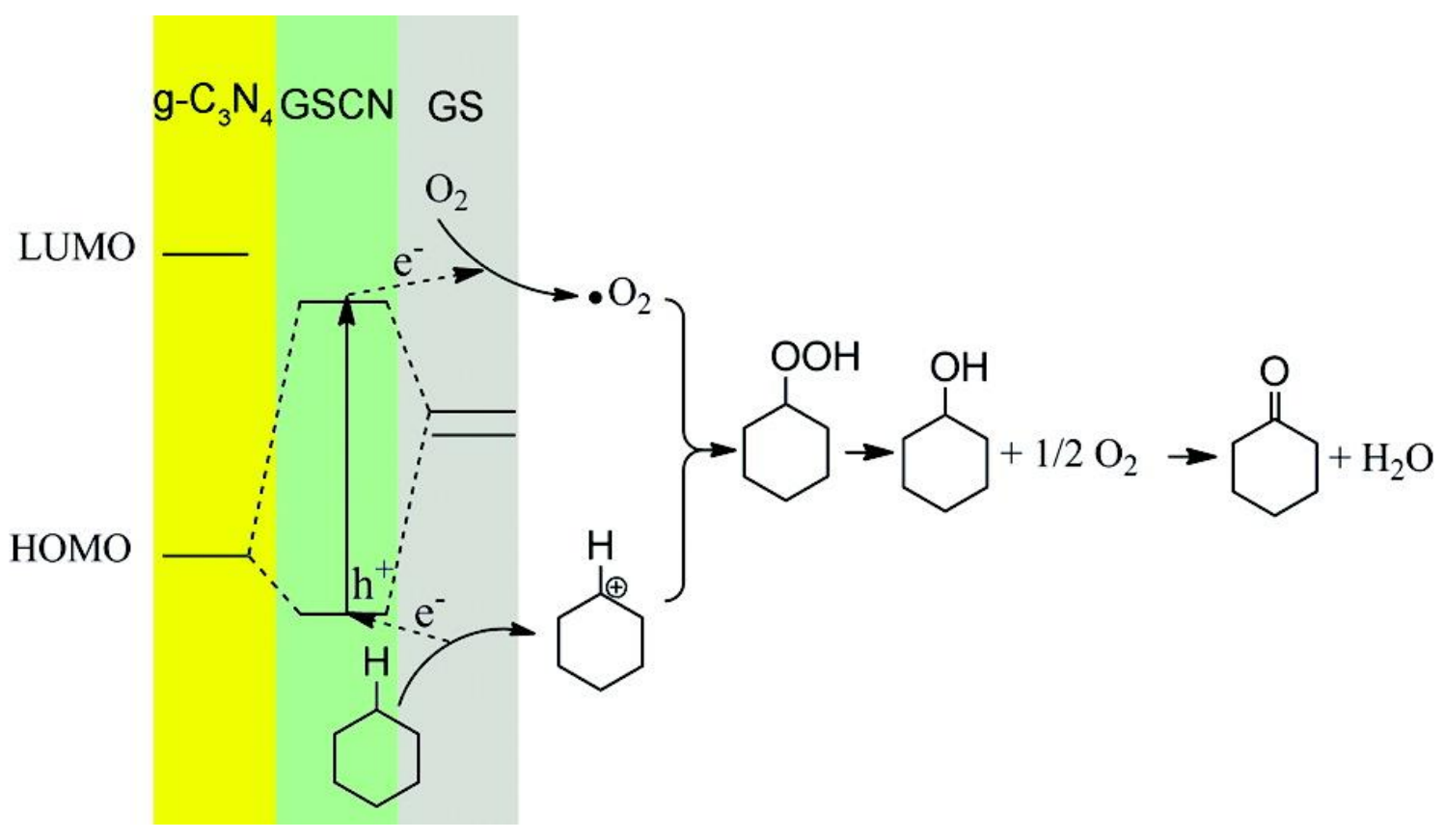

Figure 9: $\mathrm{g}-\mathrm{C}_{3} \mathrm{~N}_{4}+$ Graphene sheet junction to activate $\mathrm{O}_{2}$ for the selective oxidation of secondary $\mathrm{C}-\mathrm{H}$ bonds of cyclohexane. In the interface, a formal charge transfer state is created (there the molecular orbital scheme) which even strengthens the oxidation power and localized hole and electron in the two material interphases (Taken with permission from Ref. 139)

\section{Summary of the current state of the art of carbocatalysis and future developments}

It was shown that nanostructured carbonaceous materials are indeed metal-free catalysts for a large diversity of different organic reactions, well beyond radical chain aerobic oxidations, and include even some reaction types in which transition metals were considered necessary, such as, the Fenton oxidation, hydrogenations, and $\mathrm{C}-\mathrm{C}$ couplings. Considering the research interest that is currently attracted by carbon catalysis, we are sure that many other reaction types will be described in the near future as being catalyzed by carbon materials in the absence of metals. Current approaches tend to attribute the catalytic activity to discrete substructures present on the carbonaceous frameworks such as certain functional groups and 
vacancies, while the importance of the collective properties of nanocarbon materials such as electrophilicity or work function is usually underestimated. This is well understandable, taking into account the difficulty to address the issue of the impact of the electron density in the catalysis using organic models or even calculations. The unique property of conjugated nanocarbons to offer a joint delocalized electron pool which can be modified even by distance atoms certainly add possibilities that just have started to be explored.

Besides expanding carbon catalysis to more and more reactions, another aspect of interest is to prepare more active materials, best even exceeding benchmark metal catalysts. In this area, the knowledge of the active sites should serve as a powerful tool to direct carbon synthesis. The long term goal should be to make nanocarbons the catalyst of choice for certain important reactions. Carbocatalysis indeed offer promising potential in novel areas where metal catalysts are not already well optimized or metals are notoriously weak, say for instance, biomass transformation and environmental remediation. In these areas, carbocatalysts offer as advantages their compatibility with biomass feedstocks or polluted wastes and the fact that $\mathrm{G}$ can be considered a renewable catalyst that do not need to be recovered after the reaction and can be processed with the final residue, e.g. simply burned. Since a whole set of novel reactions are seeking for suitable catalysts to be commercially implemented, there is in these cases a distinct possibility to compete with transition and precious metals to be used as catalysts at industrial scale.

The potentials of carbocatalysis however can go significantly further with the advent of zeolithe-like heteroatom doped carbons (known as "zeocarbons"). Zeocarbons can be envisaged where the catalytic activity of carbons is combined with substrate enrichment and size/steric selectivity within the controlled pore system. $(92,140)$ Such materials, contrary to inorganic zeolithes, are also electronically conducting and thus electrocatalysis or electrically 
biased chemocatalysis become exciting new options. Integrating metal particles within the nanometer and subnanometer pores of nanocarbons will result in new hybrid or "fusion" catalysts, as all nanocarbons are catalysts themselves, i.e. they represent "non-innocent" supports. In spite of the fact that carbons have delocalized electrons, heterojunction effects will set-in, and the carbons with the small metal entities might merge into an interface-driven, joint electronic system with previously unknown properties.

In spite of all those potentialities, we believe in the fact that the era of carbocatalysis is just at the beginning of an exciting phase, still full of surprises.

\section{Acknowledgements}

MA wants to thank the German Excellence Cluster Unicat and the Max Planck Society for continued support. Financial support by the Spanish Ministry of Economy and Competitiveness (CTQ 2015-69153-CO2-1, CTQ2014-53292-R, Severo Ochoa) and Generalitat Valenciana (Prometeo 2013-014) is gratefully acknowledged. N.L.S. is especially grateful to P.F.R. for his endless patience and readiness to offer unconditional support. 


\section{References}

1. R. Narayanan and M. A. El-Sayed, J. Phys. Chem. B, 2005, 109, 12663-12676.

2. P. Manickam-Periyaraman, S. M. Espinosa, J. C. Espinosa, S. Subramanian, M. Alvaro and H. Garcia, J. Environ. Chem. Eng., 2016, 4, 4485-4493.

3. S. Navalon and H. Garcia, Nanomaterials, 2016, 6, 123-125.

4. J. C. Espinosa, S. Navalon, M. Alvaro and H. Garcia, Catal. Sci. Technol., 2016, 6, 7077-7085.

5. J. C. Espinosa, S. Navalon, M. Alvaro and H. Garcia, ChemCatChem, 2015, 7, 26822688.

6. S. Navalon, A. Dhakshinamoorthy, M. Alvaro and H. Garcia, Chem. Rev., 2014, 114, 6179-6212.

7. Y. Zhai, Z. Zhu and S. Dong, ChemCatChem, 2015, 7, 2806-2815.

8. Z. S. Wu, Y. Sun, Y. Z. Tan, S. B. Yang, X. L. Feng and K. Müllen, J. Am. Chem. Soc. 2012, 134, 19532-19535.

9. V. Singh, D. Joung, Zhai, S. Das, S. I. Khondaker and S. Seal, Prog. Mater. Sci., 2011, $56,1178-1271$.

10. XQ. Wang, XQ, JS Lee, Q. Zhu, J. Liu, Y. Wang, S. Dai, S, Chem. Mater. 2010, 22, 2178-2180

11. W. Kicinski, M. Szala, and M. Bystrzejewski, Carbon, 2014, 68, 1-32.

12. J. Lee, J. Kim, and T. Hyeon, Adv. Mater., 2006, 18, 2073-2094.

13. W. Yang, T-P Fellinger and M. Antonietti, J. Am. Chem. Soc. 2011 133, 206-209

14. J. Stenhouse. Chem. Gaz. 1854, 13; Pharm. J. Trans. xiii. 454; Ann. Ch. Pharm. xc. 286.

15. F. Crace Calvert, Ph.D., F.R.S. J. Chem. Soc., 1867, 20, 293-296.

16. E. K. Rideal and W. M. Wright, J. Chem. Soc., Trans., 1925,127, 1347-1357.

17. Y. Iwasawa, H. Nobe and S. Ogasawara, J. Catal,. 1973, 31, 444-449.

18. M.F.R. Peirera, J.J.M. Orfao and J.L. Figuerdo, Appl. Cat. A, 2001, 218, 307- 318.

19. G. Mestl, N.I. Maksimova, N. Keller, V.V. Roddatis and R Schlögl, ACIE 2001, 40, 2066-2069. 
20. H. Peter Boehm, G. Mair, T. Stoehr, A. R. De Rincón and B. Tereczki, Fuel, 1984, 63, 8, 1061-1063.

21. J. Zhang., D. S. Su, A. Zhang, D. Wang, R. Schlögl and C. Hebert, ACIE 2007. 46, $7319-7323$.

22. J. Zhang, X. Liu, R. Blume, A. Zhang, R. Schlögl and D.S. Su, Science 2008, 322, 7377.

23. D. R. Dreyer, H. P. Jia and C. W. Bielawski, Angew. Chem. Int. Ed. Engl., 2010, 49, 6813-6816.

24. R. Demir-Cakan, P. Makowski, M. Antonietti, F. Goettmann and M-M. Titirici, Catal. Today, 2010, 150, 115-118.

25. J. Pyun, Angew. Chem. Int. Ed., 2011, 50, 1, 46-48.

26. D. R. Dreyer and C. W. Bielawski. Chem. Sci., 2011, 2, 1233-1240.

27. A. Schaetz, M. Zeltner and W. J. Stark. ACS Catal., 2012, 6, 1267-1284.

28. L. Radovic, C. Mora-Vilches and A. J. A. Salgado-Casanova, Chinese J. Catal. 2014, $35,6,792-797$.

29. C. K. Chua and M. Pumera, Chem. A Eur. J., 2015, 21, 36, 12550-12562.

30. H. Hu, JH Xin, H. Hu, X. Wang and Y. Kong, Appl. Catal. A Gen., 2015, 492, 1-9.

31. D. Sheng Su, G. Wen, S. Wu, F. Peng and R. Schlögl. Angew. Chem. Int. Ed., 2017, 56, 4, 936-964.

32. A. Primo, V. Parvulescu and H. Garcia, J. Phys. Chem. Lett., 2017, 8, 264-278.

33. A. Dhakshinamoorthy, M. Alvaro, P. Concepcion, V. Fornes and H. Garcia, Chem. Commun., 2012, 48, 5443-5445.

34. A. Dhakshinamoorthy, M. Alvaro, M. Puche, V. Fornes and H. Garcia, ChemCatChem, 2012, 4, 2026-2030.

35. H. Wang, Q. Kong, Y. Wang, T. Deng, C. Chen, X. Hou and Y. Zhu, ChemCatChem, 2014, 6, 728-732.

36. R. Wang, Z. Wu, Z. Qin, C. Chen, H. Zhu, J. Wu, G. Chen, W. Fan and J. Wang, Catal. Sci. Technol., 2016, 6, 993-997.

37. M. R. Acocella, M. Mauro and G. Guerra, ChemSusChem 2014, 7, 3279-3283.

38. L. J. Konwar, A. Samikannu, P. Mäki-Arvela, D. Boström and J-P. Mikkola. Appl. Catal. B-Environ., 2017, 220, 314-323. 
39. L. J. Konwar, P. Mäki-Arvela, N. Kumar, J-P. Mikkola, A. K. Sarma and D. Deka, React. Kinet., Mech. Cat., 2016, 119, 1, 121-138.

40. L. J. Konwar, A. Samikannu, P. Mäki-Arvela and J-P. Mikkolaa. Catal. Sci. Technol., 2018, 8, 2449-2459.

41. P. Makowski, J. Weber, A. Thomas and F. Goettmann, Catal. Commun., 2008, 10, 243247.

42. F. Su, M. Antonietti and X. Wang. Catal. Sci. Technol., 2012, 2, 1005-1009.

43. M-M. Titirici, R. J. White, N. Brun, V. L. Budarin, D. S. Su, F. del Monte, J. H. Clark and M. J. MacLachlang, Chem.Soc.Rev., 2015, 44, 250-290.

44. L. J. Konwar, J. Boro and D. Deka. Renew. Sust. Energ. Rev., 2014, 29, 546-564.

45. S.-J. Zhang, J.-H. Li, F.-J. Xiao, Y.-Y. Zheng, Q.-B. Liu, Y.-X. Fang and X. Huagong, Modern Chemical Industry, 2017, 37, 12, 28-32.

46. R. Demir-Cakan, P. Makowski, M. Antonietti, F. Goettmann and M. M. Titirici. Catal. Today, 2010, 150, 115-118.

47. J. Roeser, K. Kailasam and A. Thomas. ChemSusChem, 2012, 5, 9, 1793-1799.

48. C. A. Leon y Leon, J. M. Solar, V. Calemma and L. R. Radovic. Carbon, 1992, 30, 5, 797-811.

49. M. A. Montes-Morán, D. Suárez, J. A. Menéndez and E. Fuente. Carbon, 2004, 42, 7, 1219-1225.

50. J. Angel Menéndez, L. R. Ravovic, B. Xia and J. Phillips, J. Phys. Chem., 1996, 100 (43), 17243-17248.

51. E. Perozo, V. Calvino-Casilda, R. M. Martín-Aranda, B. Casal, C. J. Durán-Valle and M. L. Rojas-Cervantes. Appl. Surf. Sci., 2006, 252, 17, 6080-6083.

52. J. Rubio-Gómez, R. M. Martín-Aranda, M. L. Rojas-Cervantes, J. D. D. LópezGonzález and J. L. G. Fierro. Carbon, 1999, 37, 2 213-219.

53. I. J. B. Lin and C. S. Vasam, Can. J. Chem., 2005, 83, 812-825.

54. O. Kuhl, Chem. Soc. Rev., 2007, 36, 592.

55. F. Jordan, Nat. Prod. Rep. 2003, 20, 184.

56. G. A. Sprenger and M. Pohl, J. Mol. Catal. B: Enzym. 1999, 6 (3), 145.

57. M. Fèvre, J. Pinaud, Y. Gnanou, J. Vignolle and D. Taton. Chem. Soc. Rev., 2013,42, 2142-2172. 
58. M. K. Kiesewetter, E. J. Shin, J. L. Hedrick and R. M. Waymouth. Macromolecules, 2010, 43, 2093-2107.

59. J. Pinaud, J. Vignolle, Y. Gnanou and D. Taton. Macromolecules, 2011, 44, 19001908.

60. X. Zhang, G. O. Jones, J. L. Hendrick and R. M. Waymouth. Nat. Chem., 2016, 8, $1047-1053$.

61. P. Xia, M. Antonietti, B. Zhu1, T. Heil, J. Yu, and S. Cao, "Controlling Defects in Crystalline Carbon Nitride to Enable Selective $\mathrm{CO}_{2}$ Photoreduction in the Gas Phase", submitted article.

62. C. E. I. Knappke, A. Imami and A. Jacobi von Wangelin, ChemCatChem 2012, 4, 937.

63. A. Corma and H. Garcia, Chem. Rev. 2003, 103, 4307.

64. K. Gollnick, Advances in Photochemistry, 2007, 6, 1.

65. J. Zhou, Q. Wang, Q. Sun, X. S. Chen, Y. Kawazoe and P. Jena, Nano Letters, 2009, 9 3867-3870.

66. D. R. Dreyer, H.-P. Jia and C. W. Bielawski, Angew. Chem., Int. Ed. 2010, 49 (38), 6813.

67. A. Dhakshinamoorthy, A. Primo, P. Concepcion, M. Alvaro and H. Garcia, Chem. Eur. J. 2013, 19, 7547.

68. Y. Wang, H. Li, J. Yao, X. Wang and M. Antonietti, Chem. Sci. 2011, 2 (3), 446.

69. S. Caron, R. W. Dugger, S. G. Ruggeri, J. A. Ragan and D. H. B. Ripin, Chem. Rev., 2006, 106 (7), 2943.

70. A. Babuponnusami and K. Muthukumar, J. Environ. Chem. Eng. 2014, 2 (1), 557.

71. J. Herney-Ramirez, M. A. Vicente and L. M. Madeira, Appl. Catal., B, 2010, 98, 1026.

72. S. Navalon, A. Dhakshinamoorthy, M. Alvaro and H. Garcia, ChemSusChem, 2011, 4, $1712-1730$.

73. J. C. Espinosa, S. Navalon, A. Primo, M. Moral, J. Fernandez, Sanz, M. Alvaro and H. Garcia, Chem. - Eur. J., 2015, 21,11966-11971.

74. Y. Wang, Y. Xie, H. Sun, J. Xiao, H. Cao and S. Wang, ACS Appl. Mater. Interfaces, 2016, 8, 9710-9720.

75. Y. Wang, J. Zhang, X. Wang, M. Antonietti and H. Li, Angew. Chem., Int. Ed. 2010, 49 (19), 3356. 
76. G. Lv, H. Wang, Y. Yang, T. Deng, C. Chen, Y. Zhu and X. Hou, ACS Catal., 2015, 5, 5636-5646.

77. S. Navalon, A. Dhakshinamoorthy, M. Alvaro, M. Antonietti and H. Garcia, Chem. Soc. Rev. 2017, 46 (15), 4501.

78. D. W. Stephan and G. Erker, Angew. Chem., Int. Ed. 2010, 49 (1), 46.

79. A. Primo, V. Parvulescu and H. Garcia, J. Phys. Chem. Lett. 2017, 8 (1), 264.

80. B. Li and D. Su, Chem. - Eur. J., 2014, 20, 7890-7894.

81. X. Y. Sun, B. Li, T. F. Liu, J. Song and D. S. Su, Phys. Chem.Chem. Phys., 2016, 18, $11120-11124$.

82. A. Primo, F. Neatu, M. Florea, V. Parvulescu and H. Garcia, Nat. Commun. 2014, 5, 5291.

83. M.-M. Trandafir, M. Florea, F. Neatu, A. Primo, V. I. Parvulescu and H. Garcia, ChemSusChem 2016, 9, 1565-1569.

84.

85. X.-K. Kong, Z.-Y. Sun, M. Chen, C.-I. Chen and Q.-W. Chen, Energy Environ. Sci., 2013, 6, 3260-3266.

86. N. Zhang, Y. H. Zhang, M. Q. Yang and Y. J. Xu, Curr. Org. Chem., 2013, 17, 25032515 .

87. H. P. Liu, T. Ye and C. D. Mao, Angew. Chem. Int. Ed., 2007, 46, 6473-6475.

88. S. T. Yang, L. Cao, P. G. J. Luo, F. S. Lu, X. Wang, H. F. Wang, M. J. Meziani, Y. F. Liu, G. Qi and Y. P. Sun, J. Am. Chem. Soc., 2009, 131, 11308.

89. V. Strauss, J. T. Margraf, C. Dolle, B. Butz, T. J. Nacken, J. Walter, W. Bauer, W. Peukert, E. Spiecker, T. Clark and D. M. Guldi, J. Am. Chem. Soc., 2014, 136, 173081731.

90. S. N. Baker and G. A. Baker, Angew. Chem. Int. Ed., 2010, 49, 6726-6744.

91. S. W. Yang, W. Li, C. C. Ye, G. Wang, H. Tian, C. Zhu, P. He, G. Q. Ding, X. M. Xie, Y. Liu, Y. Lifshitz, S. T. Lee, Z. H. Kang and M. H. Jiang. Adv. Mater., 2017, 29, 16.

92. J. Mahmood, E. K. Lee, M. Jung, D. Shin, I. Y. Jeon, S. M. Jung, H. J. Choi, J. M. Seo, S. Y. Bae, S. D. Sohn, N. Park, J. H. Oh, H. J. Shin and J. B. Baek. Nat. Commun., 2015, 6, 6486.

93. N. Fechler, N. P. Zussblatt, R. Rothe, R. Schloegl, M. G. Willinger, B. F. Chmelka and M. Antonietti. Adv. Mater., 2016, 28, 6, 1287-1294. 
94. F. Su, S. C. Mathew, G. Lipner, X. Fu, M. Antonietti, S. Blechert and X. Wang, J. Am. Chem. Soc., 2010, 132 (46), 16299.

95. X. Wang, S. Blechert and M. Antonietti, ACS Catalysis, 2012, 2, 1596-1606.

96. A. Savateev, I. Ghosh, B. König and M. Antonietti, Angew. Chem. Int. Ed., 2018, accepted manuscript.

97. M. Antonietti and M. Oschatz, Adv Mater., 2018, 30, 1706836-1706846.

98. B. Kurpil, A. Savateev, V. Papaefthimiou, S. Zafeiratos, T. Heil, S. Ozenler, D. Dontsova and M. Antonietti, Appl. Catal. B-Environl, 2017, 217, 622-628.

99. F. Wöhler, Ueber das Chinon. In: Pharmaceutisches Centralblatt. 1844, 39, 609-615.

100. B. H. Han, D. H. Shin and S. Y. Cho, Tetrahedron Lett., 1985, 26, 6233-6234.

101. B. J. Li and Z. Xu, J. Am. Chem. Soc., 2009, 131, 16380-16382.

102. Y. J. Gao, D. Ma, C. L. Wang, J. Guan and X. H. Bao, Chem. Commun., 2011, 47, 2432-2434.

103. S. Wu, G.Wen, X. Liu, B. Zhong and D. S. Su, ChemCatChem, 2014, 6, 1558-1561.

104. A. Corma, P. Concepcion and P. Serna, Angew. Chem., Int. Ed., 2007, 46, 7266-7269.

105. A. Primo, A. Forneli, A. Corma and H. Garcia, ChemSusChem 2012, 5, 2207.

106. R. Srivastava, D. Srinivas and P. Ratnasamy, Micropor. Mesopor. Mater. 2006, 90 (13), 314 .

107. F. Goettmann, A. Thomas and M. Antonietti, Angew. Chem., Int. Ed. 2007, 46 (15), 2717.

108. F. Goettmann, A. Fischer, M. Antonietti and A. Thomas, Angew. Chem. Int. Ed., 2006, $45,4467-4471$.

109. F. Goetmann, A. Fischer, M. Antonietti and A. Thomas, New J. Chem., 2007, 31, 8, $1455-1460$.

110. Y. Gao, P. Tang, H. Zhou, W. Zhang, H. Yang, N. Yan, G. Hu, D. Mei, J. Wang and D. Ma, Angew. Chem., Int. Ed., 2016, 55, 3124-3128.

111. F. Hu, M. Patel, F. Luo, C. Flach, R. Mendelsohn, E. Garfunkel, H. He and M. Szostak, J. Am. Chem. Soc., 2015, 137, 14473-14480.

112. N. Kausar, I. Roy, D. Chattopadhyay and A. R. Das, $R S C A d v ., 2016,6,22320-22330$.

113. M.-M. Trandafir, M. Florea, F. Neatu, A. Primo, V. I. Parvulescu and H. Garcia, ChemSusChem, 2016, 9, 1565-1569. 
114. J. Long, X. Xie, J. Xu, Q. Gu, L. Chen and X. Wang, ACS Catal., 2012, 2, 622-631.

115. F. Chen, Y. Xie, J. He and J. Zhao, J. Photochem. Photobiol. A, 2001, 138, 139-146.

116. X. Duan, Z. Ao, H. Sun, S. Indrawirawan, Y. Wang, J. Kang, F. Liang, Z. H. Zhu and S. Wang, ACS Appl. Mater. Interfaces, 2015, 7, 4169-4178.

117. H. Q. Sun, Y. X. Wang, S. Z. Liu, L. Ge, L. Wang, Z. H. Zhu and S. B. Wang, Chem. Commun., 2013, 49, 9914-9916.

118. X. L. Li, H. L. Wang, J. T. Robinson, H. Sanchez, G. Diankov and H. J. Dai, J. Am. Chem. Soc., 2009, 131, 15939-15944.

119. C. D. Wang, Y. A. Zhou, L. F. He, T. W. Ng, G. Hong, Q. H. Wu, F. Gao, C. S. Lee and W. J. Zhang, Nanoscale, 2013, 5, 600-605.

120. R. P. Rocha, A. G. Goncçalves, L. M. Pastrana-Martınez,B. C. Bordoni, O. S. G. P. Soares, J. J. M. Orfao, J. L. Faria, J. L. Figueiredo, A. M. T. Silva and M. F. R. Pereira, Catal. Today, 2015, 249, 192-198.

121. X.-K. Kong, Q.-W. Chen and Z.-Y. Lun, J. Mater. Chem. A, 2014, 2, 610-613.

122. H. Li, J. Liao, Y. Du, T. You, W. Liao and L. Wen, Chem. Commun., 2013, 49, 17681770 .

123. X. Duan, K. O’Donnell, H. Sun, Y. Wang and S. Wang, Small, 2015, 11, 3036-3044.

124. R. J. White, M-G. Willinger, M-M. Titirici and M. Antonietti, Green Chem., 2012, 14, 1515-1523.

125. X. Duan, K. O’Donnell, H. Sun, Y. Wang and S. Wang, Small, 2015, 11, 3036-3044.

126. B. Dai, K. Chen, Y. Wang, L. Kang and M. Zhu, ACS Catal. 2015, 5, 2541-2547.

127. X. Li, X. Pan, L. Yu, P. Ren, X. Wu, L. Sun, F. Jiao and X. Bao, Nat. Commun., 2014, $5,3688-3694$.

128. X. Li, Y. Wang, L. Kang, M. Zhu and B. Dai, J. Catal., 2014, 311, 288-294.

129. M. Conte, A. F. Carley, C. Heirene, D. J.Willock, P. Johnston, A. A. Herzing, C. J. Kiely and G. J. Hutchings, J. Catal., 2007, 250, 231-239.

130. M. A. Patel, F. Luo, M. R. Khoshi, E. Rabie, Q. Zhang, C. R. Flach, R. Mendelsohn, E. Garfunkel, M. Szostak and H. He, ACS Nano, 2016, 10, 2305-2315.

131. J. Long, X. Xie, J. Xu, Q. Gu, L. Chen and X. Wang, ACS Catal., 2012, 2, 622-631. 
132. D. I. Enache, J. K. Edwards, P. Landon, B. Solsona-Espriu, A. F. Carley, A. A. Herzing, M. Watanabe, C. J. Kiely, D. W. Knight and G. J. Hutchings, Science, 2006, 311, 362-365.

133. H. L. Liu, Y. L. Liu, Y. W. Li, Z. Y. Tang and H. F. Jiang, J. Phys. Chem. C, 2010, $114,13362-13369$.

134. J. Zhu, P. C. Wang and M. Lu, Appl. Catal., A, 2014, 477, 125-131.

135. K. Gong, F. Du, Z. Xia, M. Durstock and L. Dai, Science, 2009, 323, 760-764.

136. S. Sabater, J. A. Mata and E. Peris, Organometallics, 2015, 34, 1186-1190.

137. X. H. Li and M. Antonietti, Chem. Soc. Rev., 2013, 42, 6593-6604.

138. X.-H. Li, J.-S. Chen, X. Wang and M. Antonietti, J. Am. Chem. Soc., 2011, 133, 80748077.

139. X.-H. Li, J.-S. Chen, X. Wang, J. Sun, M. Antonietti, J. Am. Chem. Soc., 2011, 133 (21), 8074

140. Z. Tian, N. Fechler, M. Oschatz, T. Heil, J. Schmidt, S. Yuan and M. Antonietti., J. Mater. Chem. A., 2018, accepted manuscript.

141. JH. Mao, HG Zhang, YH Jiang,Y. Pan, M. Gao, WD Xiao, HJ Gao, J. Am. Chem.Soc. 2009 131, 14136

142. XF Liu, M. Antonietti, Adv.Mater. 2013, 25, 6284-6290

143. DW. Stephan, Acc. Chem. Res. 2015, 48, 306-316 